NBER WORKING PAPERS SERIES

\title{
THE DYNAMICS OF PRODUCTIVITY IN THE TELECOMMUNICATIONS EQUIPMENT INDUSTRY
}

\author{
G. Steven Olley
}

Ariel Pakes

Working Paper No. 3977

\section{NATIONAL BUREAU OF ECONOMIC RESEARCH 1050 Massachusetts Avenue \\ Cambridge, MA 02138 \\ January 1992}

Both authors are research associates of the Center for Economic Studies of the U.S. Bureau of the Census, and much of the research reported on here was carried out at the CES. We are grateful to the staff of that center, particularly Robert McGuckin, Tim Dunne, Bob Bechtold, Jim Monahan, Cyr Linonis, Al Nucci and Mark Doms, for their comments and assistance. Helpful comments were also provided by Don Andrews, Gary Chamberlain, Emest Berndt, Zvi Eckstein, Mel Fuss, Zvi Griliches, and Jerry Hausman. This paper is part of NBER's research programs in Industrial Organizations and Productivity. Any opinions expressed are those of the authors and not those of the National Bureau of Economic Research. 
NBER Working Paper \#3977

January 1992

\title{
THE DYNAMICS OF PRODUCTIVITY IN THE \\ TELECOMMUNICATIONS EQUIPMENT INDUSTRY
}

\begin{abstract}
Technological change and deregulation have caused a major restructuring of the telecommunications equipment industry over the last two decades. We estimate the parameters of a production function for the equipment industry and then use those estimates to analyze the evolution of plant level productivity over this period. The restructuring involved significant entry and exit and large changes in the sizes of incumbents. Since firms' choices on whether to liquidate and on the quantities of inputs demanded should they continue depend on their productivity, we use an equilibrium model to suggest an estimation algorithm that takes into account the relationship between productivity on the one hand, and both input demand and survival on the other. A fully parametric version of the estimation algorithm would be both comutationally burdensome and require a host of auxiliary assumptions. So we develop a semiparametric technique which is both consistent with a quite general version of the theoretical framework and easy to use.

The algorithm produces markedly different estimates of both production function parameters and of productivity movements than traditional estimation procedures. We find an increase in the rate of industry productivity growth after deregulation. This in spite of the fact there was no increase in the average of the plants' rates of productivity growth, and there was actually a fall in our index of the efficiency of the allocation of variable factors conditional on the existing distribution of fixed factors. Deregulation was, however, followed by a reallocation of capital towards more productive establishments (by a down sizing, often shutdown, of unproductive plants and by disproportionate growth of productive establishments) which more than offset the other factors' negative impacts on aggregate productivity.
\end{abstract}

G. Steven Olley Department of Economics New York University New York, NY 10003
Ariel Pakes

Department of Economics

Box 1972 - Yale Station

Yale University

New Haven, CT 06520-1972

and NBER 
There has been a major restructuring of the U.S. telecommunications equipment industry over the last two decades, and it can be explained, in large part, by a combination of two related factors. One was technological change which led to the development of many new products (eg. digital switching equipment and fiber optics). The other factur was a gradual liberalization of the regulatory environment (in both the provision of telecommunication services and in the use of telecommunications equipment) which culminated in the divestiture of AT\&T in January of 1984. Together these changes provided many new firms, both foreign and domestic, an opportunity to enter the industry, and caused dramatic changes in the profitability of incumbents. This paper estimates the parameters of a production function for the equipment industry, and then uses those estimates to analyze changes that occurred in the distribution of plant level performance from 1974 to 1987, paying particular attention to the impact of the regulatory and technological changes on aggregate productivity. In doing so we provide both a micro framework for empirically analyzing the impact of policy (and/or environmental) changes on productivity, and an estimator for production function parameters that is consistent with a behavioral model which enables a more detailed analysis of changes in industry structure and performance.

The empirical analysis is based on an extremely rich plant-level panel constructed from data collected by the U.S. Bureau of the Census. It is clear from the data that during the period under investigation the restructuring of the industry involved significant entry and exit, and large changes in the size of continuing establishments. It is worth noting that related empirical work indicates that it is not uncommon to find manufacturing industries with entry, exit, and gross job flow rates similar to those found in our data (this work dates back at least to Wedervang,1965; for more recent analyses see Baldwin and Gorecki,1988, Dunne, Roberts, and Samuelson 1988, and Davis and Haltwinger,1990) . The restructuring does, however, highlight two estimation problems. If firms' 
choices on whether or not to liquidate, and on the quantities of inputs demanded should they continue, depend on productivity movements (and as we show below the data indicate that they do), the algorithm designed to estimate the parameters of the production function should take into account the relationship between productivity, on the one hand, and both survival and input demands, on the other. To guide us in building such an algorithm we introduce a dynamic model of firm behavior that allows for firm specific sources of efficiency that evolve over time, and for entry and exit.

From the standpoint of estimation, the theoretical model provides us with a strategy for controlling for both the self-selection induced by liquidation, and for the simultaneity induced by the endogeneity of input choices (the latter being a problem that dates back at least to the classic work of Marschak and Andrews,1944). Direct implementation of the theoretical solution to these problems would be both computationally burdensome, and require a host of auxiliary (largely functional form) assumptions. So we develop a semiparametric estimation technique which is both consistent with a quite general version of the theoretical framework, and easy to use.

The remainder of this introduction provides a short summary of our findings. First, the theory implies that failure to control for the selection and simultaneity problems should generate very particular biases in traditional estimates of production function parameters (biases that can explain familiar anomalies in those estimates). The empirical results verify these biases, and show that they can be very large. Indeed, in our particular case the corrected estimate of the capital coefficient is more than double that obtained through traditional estimation procedures, and the corrected estimate of the labor coefficient is over thirty percent lower. The corrections also generate a noticeably different time path for aggregate productivity. The theory implies positive biases in the traditional productivity figures, and we find that, in our data, the average annual bias in these figures was over a hundred per cent (and the bias varied significantly from sub period to sub period).

The corrected time path for productivity still shows a doubling in the rate of 
aggregate industry productivity growth in the post 1984 period; from an average of $.65 \%$ per year from 1974 to 1984 inclusive, to $1.2 \%$ per year from 1984 to 1987 . Part of the advantage of the micro framework is that, by allowing us to disaggregate, it allows us to search for the sources of this change in productivity growth.

We show first that the aggregate productivity increase does not seem to be a result of a more efficient allocation of variable factors of production conditional on the existing distribution of state variables among plants (the joint distribution of capital, productivity, and age). We define our index of variable factor allocative efficiency as the ratio of the minimum variable cost of producing the observed industry output conditional on the existing distribution of state variables, to the actual variable cost of production. We find that this index actually falls in the period after deregulation. Note, however, that since we expect a near monopoly to allocate production among plants to minimize the total cost of production, but do not expect such behavior from say, Nash competitors, we should not be too surprised by this finding. On the other hand, it does imply that the increase in the growth rate of industry efficiency that followed deregulation came from either a reallocation of fixed inputs to more productive enterprises, or from an increase in the average of the plant level rates of productivity growth.

To investigate these possibilities further we show that one can decompose the index of aggregate productivity into a sum of two terms. The first is the (unweighted) average of the productivities of the active plants, and the second is the plant level covariance of output and productivity. The higher the covariance, the more efficient the allocation of output conditional on the plant level distribution of productivities (i.e. allowing capital to be mobile). There is no evidence that the average productivity of the plants in the sample increased faster in the post 1984 period. The realized productivity gains seem to be entirely a result of a reallocation of output to more productive plants. We already noted that this was not a result of more variable factors being allocated to firms whose capital-productivity combinations warranted it. Apparently the increased competition 
brought on by deregulation forced a dramatic shift in the allocation of capital towards the more productive plants. This tendency is verified by computing movements in the correlation of capital and productivity over the period, and by analyzing the relationship between shutdown frequencies, on the one hand, and capital, age, and productivity, on the other. It was both a result of the down sizing (frequently the shutdown) of (often older) unproductive plants, and the disproportionate growth of productive establishments (often new entrants).

Note that the "industry's" response to the changes in its environment was a complicated dynamic process involving capital expansion in some plants, contraction in others, and large amounts of entry and exit. A more detailed analysis of either how different primitives affected this process, or of the processes' implications on say, welfare, or on gross job flows, would require both further details on the industry (details that are currently buried in the nonparametric part of our specification), and an algorithm capable of computing the implications of the equilibrium framework that underlies our estimation technique (see Pakes and McGuire, 1991, for an example of such an algorithm).

What does seem to be clear, however, is that there were large differences among plants in their efficiency in generating sales from capital and labor expenditures and that these differences in their sales generating ability (which we label productivity) were an important determinant of how the plants fared as a result of the regulatory and technological changes of the period. Moreover it was largely the differences in how plants of different productivities fared that determined the changes in aggregate industry performance over this period. It follows that to analyze the processes that translated the regulatory and technological changes into aggregate productivity growth we had to work at a fairly detailed level of micro analysis. That is the processes that the data singled out as being important could not (for the most part) be analyzed with aggregate data, or even with balanced panels (panels which do not inciude information on either entrants, or on firms which eventually exit). 
The first séction of the paper provides a brief history of the telecommunications equipment industry and documents some of the relevant changes in regulatory structure. It also presents an overview of the data used in the analysis. Section 2 summarizes the theoretical model used to guide estimation, while section 3 provides the estimation algorithm and presents the parameter estimates. Section 4 uses our estimates to analyze the evolution of industry level productivity and compares the results implied by our procedures to those obtained from more traditional methods of analysis. We conclude with two caveats on the interpretation of our results. Two appendices follow. The first discusses the data, and the second provides the variance covariance matrix of our parameter estimates.

\section{Overview of the Industry.}

We begin with a brief review of recent developments in the telecommunications industry. This will both help to focus the subsequent modeling exercise, and enable us to obtain a deeper understanding of the empirical results.

Beginning in the early 1970 's, the telecommunications industry entered into a period of rapid change. The changes were a result of a combination of significant technological developments in telecommunications equipment and a gradual liberalization of the regulatory environment governing the provision of telecommunications services. Together these developments have led to a substantial restructuring of the competitive environment in the U.S. telecommunications equipment industry. For the purposes of this study, we include in our definition of the industry practically all types of customer premise and network telecommunications equipment, with the exception of the various types of transmission media, including copper wire, coaxial cable, and glass fiber (for details, see the appendix).

For most of the twentieth century, American Telephone and Telegraph (AT\&T) maintained an exclusive monopoly in the provision of telecommunications services and, 
through their procurement practices, extended that dominant position into the equipment industry. ${ }^{1}$ This position was achieved initially by having control of the telephone patent, but AT\&T's dominance in the equipment market was maintained by the requirement that any equipment that was attached to the Bell system network had to be supplied by AT\&T itself. Prior to the AT\&T divestiture, Western Electric, AT\&T's manufacturing subsidiary, supplied approximately $90 \%$ of AT\&T's equipment purchases. ${ }^{2}$ Given the fact that AT\&T was by far the largest purchaser of telecommunications equipment, entry into the equipment market was effectively prohibited.

At the manufacturing level, barriers to entry seemed to be no greater than in other electrical appliance industries. ${ }^{3}$ The effective barrier to entry came from restrictions in the market for users of the equipment. An end-user could not legally attach a telephone set, or any other piece of terminal equipment, to the public network. This, together with the fact that AT\&T purchased equipment almost solely from Western Electric, meant that the only method of entry into the private equipment market was to establish a telephone company, a strategy that was generally prohibited by state regulatory authorities. As a result, Western Electric was relatively free from competitive pressures in the equipment market.

In recent years, however, Western Electric's dominance in the equipment market has faded.4 This is partially a result of the transition from electromechanical to fully electronic technology in both the switching and transmission of signals, a shift that has

See Brock (1981), p.234.

2Office of Telecommunications (1986), p.23. Also see NTIA (1988) pp. 322-323.

3See Brock (1981), p.235, or Temin who writes "there does not seem now nor has there been in the past an economic argument explaining why competition could not exist in the sale of telecommunications equipment," Temin(1987), p. 335.

TThis is evidenced by the fact that in 1982 the Census of Manufactures published for the first time the four-firm concentration ratio for SIC 3661, Telephone and Telegraph Apparatus. In previous years this number had been suppressed for disclosure purposes. See also NTIA (1988) pp. 305-350, and Temin (1987) for discussion of developments in the equipment industry. 
opened up many new markets for telecommunications equipment (multiplexers, modems, facsimile machines,...). At the same time, changes in the regulatory structure governing the telecommunications industry has provided new firms the opportunity to enter the equipment industry. We now turn to a brief review of the timing of these regulatory changes.

One of the first important decisions in the trend to allow increased competition in the telecommunications equipment industry was the 'Carterfone' decision of 1968 . In that case, the Carter Electronics Company won an antitrust suit against AT\&T after ATLT had prevented Carter from connecting a private two-way radio system to the network. The Carterfone decision, and subsequent rulings by the Federal Communications Commission (the FCC) in support of the decision, paved the way for the interconnection of private equipment to the public network.

The conditions restricting entry into the telecommunications equipment market were further eroded in 1975 when the FCC established a registration and certification program to allow for the connection of private subscriber equipment to the network, in effect extending the Carterfone decision to all equipment that met FCC standards. By 1978 the program included PBX's, key telephone sets, and telephones. Thus, the tie between the telephone service providers and the equipment industry had finally been broken.

The result of these changes was sustained entry into the U.S. telecommunications equipment industry between 1967 and 1987.5 There was a surge in entry that began in the late 1960's and continued into the 1970's, as many small firms sought to take advantage of the Carterfone decision and the markets that opened up as a result of the registration and certification program. Table 1 documents this fact (for more details on the construction of the database used in this and subsequent tables see Appendix 1 and Olley, 1990). Between

sFor example, there were only four PBX manufacturers in 1969, but there were over thirty of them by 1980 (National Academy of Engineering,1984, p. 86). 


\begin{tabular}{||c|c|c|c|c|c||}
\hline \multicolumn{7}{|c|}{ Table 1 } \\
Characteristics of the Data \\
\hline Year & Plants & Firms & $\begin{array}{c}\text { Shipments } \\
\text { (billions } \\
\text { current \$) }\end{array}$ & $\begin{array}{c}\text { Shipments } \\
\text { (bili ions } \\
1982 \text { \$) }\end{array}$ & Employment \\
\hline 1963 & 133 & 104 & 2.587 & 5.865 & 136899 \\
\hline 1967 & 164 & 131 & 3.618 & 8.179 & 162402 \\
\hline 1972 & 302 & 240 & 6.222 & 11.173 & 192248 \\
\hline 1977 & 405 & 333 & 11.138 & 13.468 & 192259 \\
\hline 1982 & 473 & 375 & 20.319 & 20.319 & 222058 \\
\hline 1987 & 584 & 481 & 25.500 & 22.413 & 184178 \\
\hline & & & & & \\
\hline
\end{tabular}




\begin{tabular}{|c|c|c|c|c|c|}
\hline & & $\begin{array}{r}T \\
\text { com }\end{array}$ & $\begin{array}{l}2 \\
\text { purcha }\end{array}$ & & \\
\hline & $\begin{array}{r}\text { Bel } \\
\text { (percen }\end{array}$ & $\begin{array}{l}\text { any } E \\
\text { hases }\end{array}$ & $\begin{array}{l}\text { oment Pr } \\
\text { om west }\end{array}$ & $\begin{array}{l}\text { ment } \\
\text { ectri }\end{array}$ & \\
\hline Time & 1982 & 1983 & 1984 & 1985 & $1986_{E}$ \\
\hline & 92.0 & 80.0 & 71.8 & 64.2 & 57.6 \\
\hline $\begin{array}{l}\text { E - Es } \\
\text { Source: }\end{array}$ & $\begin{array}{l}\text { Eed for } \\
\text { A }(1988\end{array}$ & 36, & iscus & . 33 & \\
\hline
\end{tabular}


1967 and 1972 both the number of plants and the number of firms in the industry almost doubled and, as the table shows, there was also substantial entry between all subsequent censuses.

Though by 1982 the regulatory environment had changed significantly, AT\&T still remained the largest service provider in the United States and, as a result, the largest purchaser of telecommunications equipment. Consequently, as long as AT\&T continued its practice of buying most of its equipment from its manufacturing subsidiary, Western Electric maintained a dominant position in the equipment industry, even in the face of the changes in the regulatory environment. The 1982 Consent Decree changed this situation dramatically. The agreement, which was signed in January 1982 and implemented in January 1984, called for the divestiture of AT\&T's regional operating companies. The seven regional Bell operating companies (RBOC) that were created from the Consent Decree are all very large companies in their own right. For our study of the telecommunications equipment industry it is important to note that as a result of the divestiture the RBOC's are free to purchase equipment from any supplier they choose, but are prohibited from manufacturing equipment themselves. The effect of the Consent Decree on the purchases of equipment by Bell system companies is illustrated rather dramatically in Table 2.

Table 1 only tells part of the entry story. In addition to generating increased competition from U.S. manufacturers, the regulatory changes also induced growing competition from several large foreign producers. In both 1972 and 1977 imports accounted for only $2 \%$ of new supply, and even by 1982 that share had only reached $4 \%$. However the share of imports to new supply rose steadily from 1982 onwards. By 1987 imports make up fully $14 \%$ of new supply. ${ }^{\circ}$ Note also that the increase in the share of imports can account

'See U.S. Industrial Outlook, various years. The largest of the foreign suppliers include the Canadian firms of Northern Telecom and Mitel, Siemens from West Germany, Ericsson from Sweden, and the Japanese firms of NEC, ATI/Fujitsu, Iki, and HItachi. 
for a large part of the observed fall in domestic employment between 1982 and 1987 observed in Table 1. Of course the import figures understate the share of the domestic market that the foreign suppliers were able to capture, since many of the foreign owned suppliers have established manufacturing facilities in the U.S..

Table 3 provides an indication of the overall importance of the entry process (at least in terms of domestic production). It lists: the absolute number of new plants and new firms since 1972 (and since 1982) that are still active in 1987; the new plants and new firms as a percent of the total number of plants and firms active in 1987; and the shares of the new plants and the new firms in both the shipments and the employment of 1987. Almost $90 \%$ of the firms, and $80 \%$ of the plants, active in 1987 had entered since 1972 and the new entities accounted for over $30 \%$ of shipments and almost $40 \%$ of employment. Indeed many of the new entrants entered after 1982 (though, as one should expect, the later entrants tended to be smaller as of 1987$).^{7}$

Table 4 provides an indication of the importance of the exit or liquidation process. It provides: the fraction of plants (firms) that were active in 1972 (1982) that did not survive until 1987; the share of these entities in 1972 shipments; and their share of 1972 employment. $60 \%$ (70\%) of the plants (firms) that were active in 1972 did not survive until 1987 and these plants (firms) accounted for $40.2 \%$ (13.8\%) of 1972 employment and $39 \%(12.1 \%)$ of 1972 shipments. Indeed, over $40 \%$ of the plants that were active in 1982 did not survive until 1987, and these plants produced about $25 \%$ of 1982 output . ${ }^{8}$

7About 400 of the 419 new entrants were "de novo" new entrants; that is they enter by opening a new plant or transfering an existing plant into the industry. The de novo new entrants were, however, smaller in 1987 accounting for only $18.4 \%$ of 1987 shipments and $23.5 \%$ of employment.

BThere is a question of the extent to which the changes that occured in the telecommunication equipment industry during this period induced more entry and exit (and in general more "churning") than one would typically find in a manufacturing industry. Baldwin and Gorecki, 1989, provide entry and exit figures for four digit Canadian manufacturing industries which are built from a plant level panel comparable to ours. Their figures are for a ten (rather than for a fifteen) year period, but when we 


\begin{tabular}{|c|c|c|c|c|}
\hline & Table 3: & Entrants Acti & ve in 1987 & \\
\hline & Number & $\begin{array}{c}\text { Share of } \\
\text { Number Active } \\
\text { in } 1987 \\
(8)\end{array}$ & $\begin{array}{c}\text { Share of } \\
\text { Shipments } \\
\text { in } 1987 \\
(8)\end{array}$ & $\begin{array}{c}\text { Share of } \\
\text { Employment } \\
\text { in } 1987 \\
\text { (q) }\end{array}$ \\
\hline $\begin{array}{c}\text { Plants; New } \\
\text { Since } 1972 \\
\end{array}$ & 463 & 79.0 & 32.8 & 36.0 \\
\hline $\begin{array}{l}\text { Firms: New } \\
\text { Since } 1972 \\
\end{array}$ & 419 & 87.0 & 30.0 & 41.4 \\
\hline $\begin{array}{c}\text { Plants; New } \\
\text { Since } 1982 \\
\end{array}$ & 306 & 52.0 & 12.0 & 13.5 \\
\hline $\begin{array}{l}\text { Firms; New } \\
\text { since } 1982 \\
\end{array}$ & 299 & 60.1 & 19.4 & 27.5 \\
\hline
\end{tabular}




\begin{tabular}{|c|c|c|c|c|}
\hline Table & 4: Encumb & nts Exiting & By 1987 & \\
\hline & Number & $\begin{array}{c}\text { Share of } \\
\text { Number } \\
\text { Active in } \\
\text { Base Year } \\
(8) \\
\end{array}$ & $\begin{array}{c}\text { Share of } \\
\text { Shipments } \\
\text { in Base } \\
\text { Year (f) }\end{array}$ & $\begin{array}{l}\text { Share of } \\
\text { Employment } \\
\text { in Base } \\
\text { Year }\left(\frac{\circ}{6}\right)\end{array}$ \\
\hline $\begin{array}{c}\text { Plants active in } \\
1972 \text { but not in } \\
1987\end{array}$ & 181 & 60.0 & 40.2 & 39.0 \\
\hline $\begin{array}{c}\text { Firms active in } \\
1972 \text { but not in } \\
1987\end{array}$ & 169 & 70.0 & 13.8 & 12.1 \\
\hline $\begin{array}{c}\text { Plants active in } \\
1982 \text { but no in } \\
1987\end{array}$ & 195 & 41.2 & 26.0 & 24.1 \\
\hline $\begin{array}{c}\text { Firms active in } \\
1982 \text { but not in } \\
1987\end{array}$ & 184 & 49.1 & 17.3 & 16.1 \\
\hline
\end{tabular}


Our goal is to analyze the changes in the efficiency of production and in the distribution of productivity that accompanied the changes in the regulatory and technological environment outlined in the beginning of this section. To do so we need estimates of production function parameters. The tables in this section showed that the changes in the environment were accompanied by a great deal of entry and exit, as well as significant movement in the relative sizes of the continuing establishments. These changes in size were, as one might expect, accompanied by changes in input demand, while, as we show below, a major determinant of whether or not a plant exits is its productivity. Given that a firm's productivity is not directly observable, the fact that exit and input demand decisions are based upon it, generates both a selection and a simultaneity problem in obtaining production function estimates. To account for their impacts we need a model which determines both when exit occurs and how input decisions are made; a model that is rich enough to allow for firm specific, or idiosyncratic, sources of change and the equilibrating forces of entry and exit. We now turn to the task of outlining such a model.

\section{The Behavioral Framework.}

In obtaining our estimates of production function parameters we are confronted with two interrelated problems. First, to the extent that differences in efficiency are known to firms when they choose their inputs, and as we show below the efficiency of a given firm is highly correlated over time, our attempts to estimate production function parameters will be hindered by the classic simultaneity problem analyzed by Marschak and Andrews (1944).

multiply the figures they obtain as averages over all four digit industries by $3 / 2$ to make them comparable to the figures in tables 3 and 4 we obtain numbers for the shares of employment in new plants and firms, and the share of employment in plants and firms that eventually exit, that are very close to ours. On the other hand, their figures for the fraction of firms that are new, and the fraction of firms initially active that eventually exit, are smaller than the analogous numbers in our tables. For a recent review of the empirical literature on entry and exit see Geroski, 1991. 
Second as noted above the restructuring of the telecommunications equipment industry during the period under study was accompanied by a great deal of entry and exit. This generates the issue of how to handle attrition from, and additions to, the data during the period under study. Traditional solutions to this problem restrict the analysis to a "balanced" panel, studying only those firms that were present over the entire sample period. However, if firm's exit decisions are made, at least in part, on the basis of their perceptions of their productivity in the future, and if their perceptions of their future productivity are partially determined by the realizations of their current productivity, then by considering only those firms who survive the entire period we will be considering a sample selected, in part, on the basis of the unobserved productivity realizations. This in turn will generate a selection bias of a very particular form in both the traditional estimates of production function parameters and in the subsequent analysis of productivity.

To analyze either of these two problems, we need a more detailed dynamic model of firm behavior that allows for firm-specific efficiency differences that exhibit idiosyncratic changes over time ${ }^{9}$. To sort out the simultaneity problem, the model must specify the information available when input decisions are made. To enable us to control for the selection induced by liquidation decisions, the model must generate an exit rule.

There are several models that allow for idiosyncratic uncertainty and entry and exit that are now available (see Ericson and Pakes, 1989, Hopenhayn and Rogerson, 1989, Jovanovic 1982, and Lambson, forthcoming). The model used here combines certain

SStarting with Marschak and Andrews (1944), there is a long history of articles that recognize that one cannot evaluate alternative estimates of production function parameters without a structural model of firm behavior. Griliches, for example, writes "It is harder to make an adequate allowance for the simultaneity problem without constructing a complete production and input decision behavior model" [Griliches ,1967, pp. 277-278]. Our approach differs somewhat from the previous literature in that we use a model which is explicitly dynamic and incorporates a notion of equilibrium among firms. This allows us to account for both the changes in incumbent behavior over time and for the entry and exit observed in panel data sets. 
features of the Ericson-Pakes model and the Hopenhayn-Rogerson model. We now provide a brief summary of the aspects of those models we need in order to derive the input demand and the liquidation rules.

As in Ericson and Pakes (1989), we assume that current profits are a function of a vector of firm-specific state variables and a counting measure which simply lists the vector of state variables of all the frrm's active competitors (we shall refer to this counting measure as the market structure). In our example, the vector of state variables consists of $a_{t}$, the age of the firm, $k_{t}$, the firm's capital stock, and $\omega_{t}$, an index of the firm's efficiency; so a market structure consists of a list of these triples for all active firms.

At the beginning of every period an incumbent firm has three decisions to make. The first is to decide whether to exit or continue in operation. If it exits, it receives a sell-off value of dollars and never reappears again. If it continues in operation, it chooses variable factors (labor) which, together with the beginning period values for its state variables and, possibly, a realization of a productivity shock, determine current profits. In addition, the firm chooses a level of investment, which, together with the current capital value; determines the capital stock at the beginning of the next period.

We make the following assumption on the evolution of the state variables. The accumulation equations for capital and age are given by

$$
\text { (1) } k_{t+1}=(1-\delta) k_{t}+i_{t}
$$

and

$$
\text { (2) } a_{t+1}=a_{t}+1
$$

both of which hold with probability one. As in Hopenhayn and Rogerson (1990), the index of productivity, $\omega$, is assumed to be known to the firm and to evolve over time according to 
an exogenous Markov process. That is the distribution of $u_{t+1}$ conditional on all information known at $t$ is determined by the family of distribution functions

(3) $\mathbb{P}_{\omega}=\{P(\cdot \mid \omega), \omega \in \cap\} \cdot{ }^{10}$

The firm is assumed to maximize the expected discounted value of future net cash flows. Therefore, both the exit decision and the investment decision will depend on the firm's perceptions of the distribution of future market structures given current information. The investment, entry, and exit decisions generated by these perceptions will, in turn, generate an actual distribution for the counting measure providing the market structure in future years. Below we simply assume the existence of a Markov Perfect Nash equilibrium in investment strategies - an equilibrium where firms' perceptions of the distribution of future market structures are in fact consistent with the objective distribution of market structures that the firms' choices generate - and then use the investment and liquidation rules that result from this equilibrium to help structure estimation.

In this setting, the Bellman equation for an incumbent firm can be written as,

(4) $\quad V_{t}\left(\omega_{t^{\prime}} a_{t^{\prime}} k_{t}\right)=\max \left\{\phi, \sup _{i} \geq 0 \pi_{t}\left(\omega_{t^{\prime}} a_{t}, k_{t}\right)-c(i)+\beta E\left[V_{t+1}\left(\omega_{t+1}, a_{t+1}, k_{t+1}\right) \mid \delta_{t}\right]\right\}$, where $x_{t}(\cdot)$ is the restricted profit function giving current period profits as a function of the vector of state variables, $c(i)$ is the cost of current investment $i_{t}, \beta$ is the firm's discount factor, and $\sigma_{t}$ represents information available at time $t$. If $\phi$ is greater than the second arguement after the max operator the firm exits.

${ }^{10}$ The Ericson-Pakes (1989) model has the distribution of $\omega_{t+1}$ conditional on past history dependent on the amount of investment in $R \& D$, as well as on $w_{t}$. Unfortunately we do not have the detail on the $R \& D$ data that would make their model easy to estimate. 
Note that both the value function $\mathrm{V}(\cdot)$, and the profit function $\pi(\cdot)$, are indexed by t. This is to save notation. Were we to write out either of these functions we would find that they depend both on the market structure in the current period and on factor prices (see Pakes and McGuire,1990). Though these are assumed not to vary among firms in a given period, they are free to vary across periods, and this generates the need for the $t$ index on the profit and value functions (and on the policy functions that we now derive from them).

The max operator indicates that a firm compares the sell-off value of its plant $(\phi)$ to the expected discounted returns of staying in business until next period. If current productivity is so low that expected profits in the future do not make continuing in operation worthwhile, the frm closes down the plant. If this is not the case the firm chooses an optimal investment level (constrained to be nonegative). The solution to this control problem generates an exit rule and an investment demand function. If we define the indicator function $\chi_{t}$ to equal zero if the firm exits, then the exit rule and the investment demand equation are written, respectively, as

$$
\text { (5) } \quad \chi_{t}= \begin{cases}1 & \text { if } \omega_{t} \geq \omega_{t}\left(a, k_{t}\right) \\ 0 & \text { otherwise }\end{cases}
$$

and

$$
\text { (6) } i_{t}=i_{t}\left(\omega_{t}, a_{t}, k_{t}\right)
$$

Note that the functions $\underline{\psi}_{t}(\cdot)$ and $\mathrm{i}_{t}(\cdot)$ are determined as part of the Markov Perfect Nash equilibrium, and will generally depend on all the parameters determining equilibrium behavior. Also, the fact that both these functions are indexed by $t$ implies that both the investment rule and the liquidation decision can depend on the regulatory period 
(see below).

\section{Estimation}

We assume that the industry produces a homogeneous product with Cobb-Douglas technology, and that the factors underlying the profitability differences among firms are neutral efficiency differences.11 Therefore the production function is written as

$$
\text { (7) } \quad \gamma_{\mathrm{i}_{\mathrm{t}}}=\beta_{\mathrm{o}}+\beta_{\mathrm{a} \mathrm{at}}+\beta_{\mathrm{k}} \mathrm{k}_{\mathrm{it}}+\beta f_{\mathrm{it}}+w_{\mathrm{it}}+\eta_{\mathrm{it}}
$$

where $y_{i t}$ is the log of output (value added) from plant $i$ at time $t, a_{i t}$ is its age, $k_{i t}$ is the $\log$ of its capital input, $l_{i t}$ is the $\log$ of its labor input, $\psi_{\mathrm{it}}$ is its productivity, and $\eta_{\mathrm{it}}$ is either measurement error (which can be serialiy correlated) or a shock to productivity which is independent over time. Here both $\omega$ and $\eta$ are unobserved. The distinction between them is that $\omega$ is a state variable in the firm's decision problem, and hence a determinant of both liquidation and input demand decisions, while $\eta$ is not.

Consider first the biases in the O.L.S. estimates of (7) caused by the problems of endogeneity of the input demands and by the self-selection induced by exit behavior. The endogeneity issue arises because current input choices are determined (in part) by the firm's beliefs about likely values of $\omega_{t}$ when those inputs will be used. As a result, if there is serial correlation in $\omega_{t}$, inputs in period $t$ will be positively correlated with it, and an

1Though we maintain the assumption of Cobb-Douglas technology throughout this paper, it is easy to generalize the estimation algorithm developed below to allow for more general production technologies; translog with neutral efficiency differences across firms would, for example, do equally well. The only real limitation of the estimation algorithm is that it requires a technology that generates the invertibility condition used to go from equation (6) to (7) below (at least for some known subset of the data). This condition will be satisfied in the current framework provided the marginal productivity of capital is strictly increasing in $w$, see Pakes, 1991, Section IV, for a more detailed exposition. 
OLS procedure that fails to take account of the unobserved productivity differences will tend to provide upwardly biased estimates of input coefficients (moreover, we expect the more variable inputs to be more highly correlated with the current values of $\omega_{t}$; see Marschak and Andrews, 1944, and Griliches, 1957, for early, and more detailed, expositions).

Now consider the problem of self-selection induced by plant closings. Assuming, temporarily, that there are no variable factors (the estimation algorithm has a preliminary step which estimates their coefficients), the conditional expectation of $y_{t}$ (conditional on current inputs, survival, and information available at $t-1$ ), includes the term

$$
E\left[\omega_{t} \mid k_{t}, a_{t}, w_{t-1}, x_{t}=1\right]
$$

Now recall that $\chi_{t}=1$ if and only if $\omega_{t}>\underline{u}_{t}\left(k_{t}, a_{t}\right)$. Further it is straightforward to show that the value function (equation 4 ) is increasing in $k$ (and, if older firms are less productive conditional on the current value of their capital stock, decreasing in a). This implies that $\underline{\omega}_{t}(\cdot)$ is decreasing in $\mathrm{k}$ (increasing in a). Firms with larger capital stocks can expect larger future returns for any given level of current productivity, and hence will continue in operation at lower $v$ realizations. Thus, conditional on $w_{t-1}$ and observed inputs, the self-selection caused by exit behavior will cause the expectation of $v_{t}$ to be decreasing in $\mathbf{k}$ (increasing in a), inducing a negative bias in the capital coefficient (and a positive bias in the age coefficient). 12

Labor is assumed to be the only variable factor (so its choice can be affected by the

12The crucial part of the logic underlying the sign of these biases is that the difference between the value of continuing in operation and the sell off value of the firm be increasing in $\omega$ and $k$, and decreasing in a. Provided this condition is met, it does not matter whether the sell off value is independent of $k$ and $a$ (which, for simplicity, was the specification we used in our description of the behavioral model). For similar reasons the semiparametric techniques used in the estimation algorithm do not require the sell off value of the firm to be independent of $k$ and $a$. 
current value of $\left.\omega_{t}\right)$. The other two inputs, $k_{t}$ and $a_{t}$, are fixed factors and are only affected by the distribution of $\omega_{t}$ conditional on information at time t-1 and past values of u. In particular, recall that the solution to the firm's optimization problem, (4), resulted in the investment equation

(6) $i_{t}=i_{t}\left(w_{t}, a_{t}, k_{i}\right)$.

That is investment at time $t$ is a function of the values of the three firm specific state variables and market structure at time $t$.

Assume that, provided $i_{t}>0,(6)$ is strictly increasing in $u$, conditional on any value for the couple $(a, k)$. Then $(6)$ is invertible on the set of values for $\left(i_{t}, a_{t}, k_{t}\right)$ for which $i_{t}>0$, and for that set we can write

$$
\text { (8) } u_{t}=h_{t}\left(i_{t}, a_{t}, i_{t}\right) \text {. }
$$

Since equation (8) allows us to express the unobservable productivity variable, $v_{t}$, as a function of observables, it will enable us to solve the simultaneity problem. The invertibility condition that lies behind it states that, conditional on a particular value for the capital stock, firms with higher $\omega$ will invest more. Regularity conditions which insure that this is true for the current example are given in Pakes (1991, section IV).

Now substitute (8) into (7) to obtain

$$
\text { (9) } \quad y_{i t}=\beta l_{i t}+\phi_{t}\left(i_{i t}{ }^{\prime a}{ }_{i t}, k_{i t}\right)+\eta_{i t}
$$

where,

$$
\phi_{t}\left(i_{i t}, a_{i t}, k_{i t}\right)=\beta_{0}+\beta_{a} a_{i t}+\beta_{k} k_{i t}+b_{t}\left(i_{i t}, a_{i t}, k_{i t}\right) .
$$


Below we use equation (9) and a nonparametric (series) estimator of the function $\phi_{t}(\cdot)$ to estimate $\beta_{l}$ Note, however, that the production function coefficients of capital and age, $\beta_{a}$ and $\beta_{k}$, are not identified from this equation since the equation does not allow us to separate out the effect of capital and age on the investment decision from their effect on output.

To identify the age and capital coefficients we have to use the panel structure of the data and the model's implications regarding the relationship between the observed productivities of a given firm over time. Recall that we only observe the subsequent year's data for those plants that survive, so in order to proceed we need the probability of survival. That probability is given by

$$
\begin{gathered}
\text { (11) } \operatorname{Pr}\left\{x_{t+1}=1 \mid \underline{w}_{t+1}\left(k_{t+1}, a_{t+1}\right), \mathscr{J}_{t}\right\} \\
=\operatorname{Pr}\left\{w_{t+1} \geq \underline{w}_{t+1}\left(k_{t+1}, a_{t+1}\right) \mid \underline{w}_{t+1}\left(k_{t+1}, a_{t+1}\right), w_{t}\right\} \\
=P_{t}\left\{\underline{w}_{t+1}\left(k_{t+1}, a_{t+1}\right), w_{t}\right\} \equiv P_{t}
\end{gathered}
$$

where we have dropped the dependence of the variables on the individual subscript (i) for notational convenience. Together, the accumulation and the investment equations imply that both $a_{t+1}$ and $k_{t+1}$ can be expressed as functions of the triple $\left(u_{t}, k_{t}, a_{t}\right)$ and $w_{t}=h_{t}\left(i_{t}, a_{t}, k_{t}\right)$. So the probability in (11) can be expressed as a time dependent function of $i_{t}, a_{t}$, and $k_{t}$. Below we provide nonparametric estimators of this survival probability. We complete the system to be estimated by considering the expectation of $y_{t+1}-$ $\beta t_{t+1}$ conditional on inputs at time $t+1$ and survival. This equation, when combined with the estimates of $\beta_{l}, \phi_{t}$, and $\mathscr{l}_{\mathrm{t}}$, from (10) and (11) will allow us to identify $\beta_{\mathrm{a}}$ and $\beta_{\mathrm{k}}$. We have 


$$
\begin{gathered}
\text { (12) } \quad E\left[y_{t+1}-\beta t_{t+1} \mid a_{t+1}, k_{t+1}, x_{t+1}=1\right] \\
=\beta_{0}+\beta_{a} a_{t+1}+\beta k_{t+1}+E\left[u_{t+1} \mid \omega_{t}, x_{t+1}=1\right] \\
=\beta_{0}+\beta_{a} a_{t+1}+\beta_{k} k_{t+1}+\int_{\omega_{t+1}} \omega_{t_{t+1}} \frac{P\left(d \omega_{t+1} \mid \omega_{t}\right)}{P\left(\omega_{t} \omega_{t+1} \mid \omega_{t}\right)} \\
=\beta_{a} a_{t+1}+\beta_{k} k_{t+1}+g\left(\mathscr{P}_{t}, \omega\right)
\end{gathered}
$$

where

$$
g\left(\mathscr{P}_{t}, \omega_{t}\right) \equiv \beta_{0}+\int_{\omega_{t+1}} \omega_{t+1} \frac{P\left(d \omega_{t+1} \mid \omega_{t}\right)}{\underline{\omega}_{t+1} P\left(d \omega_{t+1} \mid \omega_{t}\right)}
$$

and the last equality assumes that the function giving the probability of survival, $\rho_{t}=$ $P_{t}\left\{\underline{\omega}_{t+1}\left(k_{t+1}, a_{t+1}\right), \omega_{t}\right\}$, is invertible for almost every $\omega_{t}$, allowing us to write $\underline{\omega}_{t+1}()$ as a function of $\Phi_{t}$ and $\omega_{t}$.

Now note that (12) and (11) together imply that

$$
y_{t+1}-\beta t_{t+1}=\beta_{\mathrm{a}} \mathrm{a}_{\mathrm{t}+1}+\beta_{\mathrm{k}} \mathrm{k}_{\mathrm{t}+1}+\mathrm{g}\left(\mathcal{\rho}_{\mathrm{t}} \phi_{\mathrm{t}}-\beta_{\mathrm{a}} \mathrm{a}_{\mathrm{t}}-\beta_{\mathrm{k}} \mathrm{k}_{\mathrm{t}}\right)+\xi_{\mathrm{t}+1}+\eta_{\mathrm{t}+1}
$$

where,

$$
\xi_{t+1}=\omega_{t+1}-E\left[\omega_{t+1} \mid \omega_{t}, x_{t+1}=1\right]
$$

Equation (13) helps clarify two points; why we need the the first stage of the estimation algorithm, and why we need an estimate of $\omega$ (in addition to 9 to make the 
selection correction. First note that the difference between $w_{t+1}$ and its expectation conditional on past history (including $v_{t}$ ) and survival, that is $\xi_{t+1}$, is mean independent of both $k_{t+1}$ and $a_{t+1}$ (since both these variables are known functions of variables available at the beginning of the period), but not of $l_{t+1}$ (since labor can adjust to realizations in current productivity). Use of the estimate of $\beta_{l}$ from the first stage allows us to remove this simultaneity problem in the choice of the labor by taking that variable over to the left hand side of the estimating equation. Second note that the exit probability depends on both $v_{t}$ and on $\underline{w}_{t+1}(\cdot)$ (which varies across firms). As a result firms with the same exit probabilities can have different expectations of $v_{t+1}$ conditional on survival.

We turn now to a brief description of the details needed to actually implement the estimation of the system given by (10),(12), and (13). The reader who is not interested in these details can turn directly to our discussion of table 6 (the bottom of page 25) where our empirical results are described.

Equation (10) is an example of one of the earliest semiparametric regression models. It has been analyzed using both kernel (Robinson, 1988) and series (Andrews 1990a and Newey 1991b) estimators of $\phi_{t}(\cdot)$ and, subject to regularity conditions, the resulting estimators of $\beta_{l}$ have the same limiting distribution. For simplicity, we use a polynomial series estimator for $\phi_{t}()$. That is we project $y_{t}$ on $l_{t}$ and a polynomial in the triple $\left(i_{t}, a_{t}, k_{t}\right)$. The empirical results presented here used a fourth order polynomial (with a full set of interactions) to approximate the $\phi_{t}(\cdot)$ equation, but there was almost no change in either the estimates of the coefficients of interest, or in the minimand, when we went from a third to a fourth order approximation. Also, since the investment function, and hence $\phi_{t}()$, should differ with changes in market structure (see 6 above), we estimated different polynomials for each of four regulatory periods $(1974 / 77,1978 / 80,1981 / 83$, and 1984/86; see the discussion in section I).

Next we consider the estimation of the selection equation in (12), the equation giving the probability of survival as a function of $\left(i_{t} a_{t}, k_{t}\right)$. Here we use both a series and $a$ 
kernel estimator of the function determining the survival probability and then compare the results. The series approximation was constructed by using a polynomial series in $\left(i_{t}, a_{t}, k_{t}\right)$ as regressors in a probit estimation algorithm (the formula the computer uses to compute the normal distribution is a series approximation to the true distribution; so this gives us a series composed with a series as our approximating function). Again we used a fourth order polynomial in $\left(i_{t}, a_{t}, k_{t}\right)$ with a full set of interactions, and again there was no change in the fit in going from the third to the fourth order. The kernel results that we present here use the bias reducing normal based kernels in Bierens (1987), though the parameter estimates were almost identical when we used a standard normal kernel. ${ }^{13}$ Again, since the model implies that both the stopping rule and the investment equation change with market structure, and changes in either of these functions will change the form of the survival probability, we ran both the kernel and the series estimator twice; once allowing for different selection equations in each of the four different regulatory periods, and once not.

Table 5 provides the correlation coefficients between $\left(\chi_{t+1}\right)$ the indicator variable for survival in period $t+1$ conditional on survival in period $t$, and the different estimates of the selection probabilities. Two points come out clearly from the table. First, the kernel estimator provides predictions (PHAT1 and PHAT2) which fit better than the series estimator (PHAT3 and PHAT4). Second, the fits are quite a bit better when we allow for different stopping rules and different investment functions in the four different regulatory regimes (compare PHAT2 to PHAT1, or in the series case, PHAT4 to PHAT3). Consequently we use PHAT2, the kernel estimates that allow for differences in the selection function in the different regulatory periods, in the analysis that follows.

13Whenever we use the bias reducing kernels in Bierens, 1987, we use a diagonal $\Omega$ with the inverse of the variance of the regressors as the diagonal elements, choose a bandwidth by cross validation, and use a degree of bias reduction of four. Standard normal kernels used a diagonal covariance matrix with the inverse of the variance of the regressors as the diagonal elements, and a bandwidth of one. 


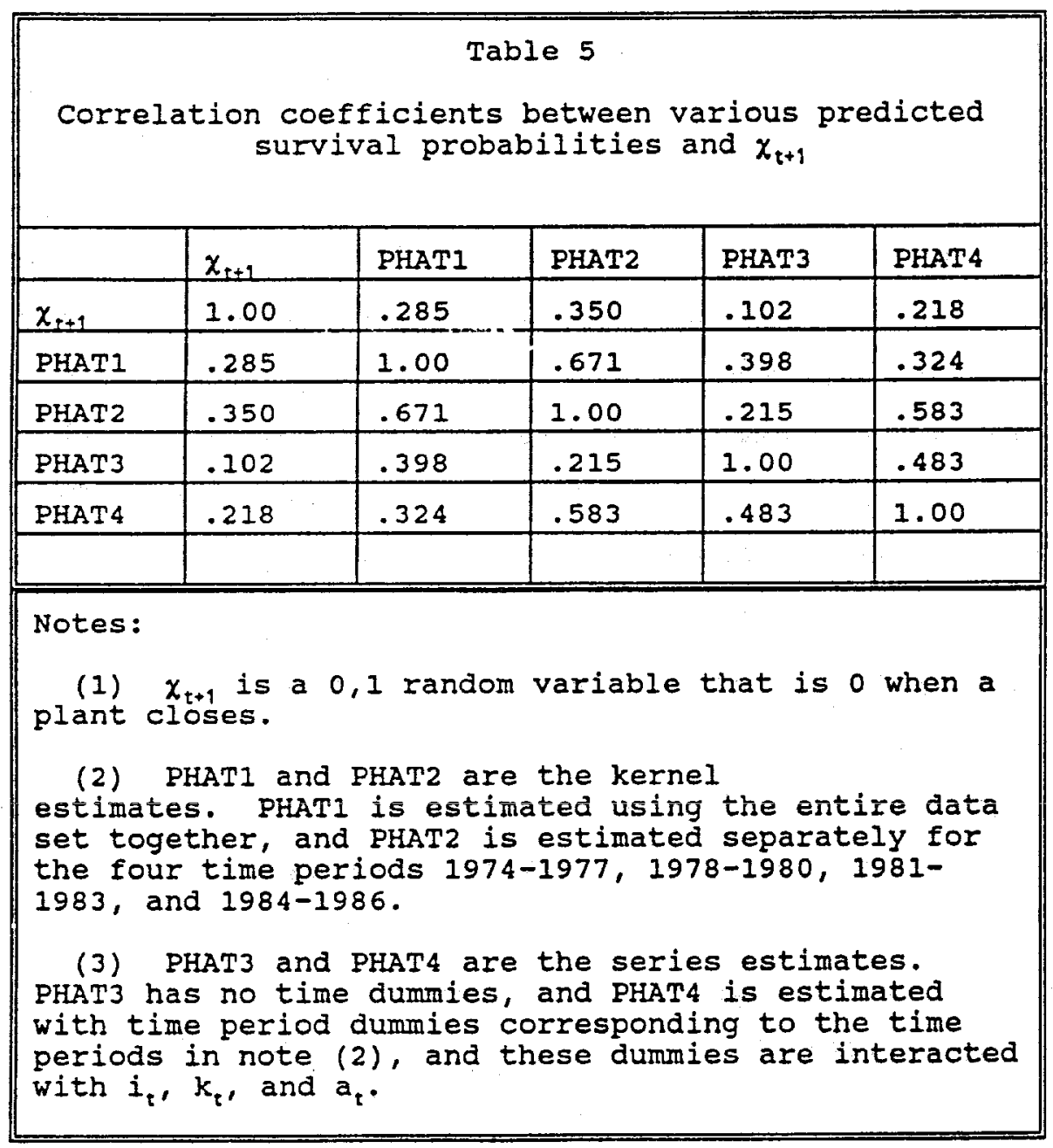


The third (and final) step of the estimation procedure takes the estimates of $\beta_{l}, \phi_{t}$ and $\rho_{t}$ from the first two steps, substitutes them into equation (13) for the true $\beta_{l}, \phi_{t}$, and $\rho_{\mathrm{t}}$, and then obtains estimates of $\beta_{\mathrm{a}}, \beta_{\mathbf{k}}$, and the $\mathrm{g}(\cdot)$ function by minimizing the sum of squared residuals in the resulting equation. Here we also try both a series and a kernel estimator of the unknown $g\left(\rho_{t}, h_{t}\right)$ function. Recall that it is $\phi_{t}$ that we estimate, and $h_{t}$ $=\phi_{t}-\beta_{a} a_{t}-\beta_{k} k_{t}$, so that the values of the regressors that determine $g()$ depend upon the values of the parameters of interest.

For the series estimator we used a fourth order polynomial expansion in $\left(h_{t}, \Phi_{t}\right)$ (and again there was almost no difference in either the sum of squares, or in the coefficients of interest, when we went from the third to the fourth order approximation). Thus the series estimate is obtained by running nonlinear least squares on the equation

$$
\left.y_{t+1}-b t_{t+1}=c+\beta_{a} a_{t+1}+\beta_{k} k_{t+1}+\Sigma_{j=0}^{4-m} \Sigma_{m=0}^{4} \beta_{\left[h^{m}\right.}{ }_{p}^{j}\right] \hat{h}_{t}^{m} \dot{\rho}_{t}^{j}+e_{t}
$$

with

$$
\dot{\mathrm{h}}_{\mathrm{t}}=\dot{\phi}_{\mathrm{t}}-\beta_{\mathrm{a}} \mathrm{a}_{\mathrm{t}}-\beta_{\mathrm{k}} \mathrm{k}_{\mathrm{t}} \text {. }
$$

$\dot{\phi}$ and $b_{l}$ are taken from the estimates of equation (10), and $\dot{\mathscr{D}}$ is taken from the kernel estimates of equation (12).

The kernel results were obtained by forming kernel estimates of the regression of

$$
y_{t+1}-b f_{t+1}-\beta_{a} a_{t+1}-\beta_{k} k_{t+1}
$$

on the regressors

$$
\dot{\rho} \text { and } \dot{h}_{\mathrm{t}}=\dot{\phi}_{\mathrm{t}}-\beta_{\mathrm{a}} \mathrm{a}_{\mathrm{t}}-\beta_{\mathrm{t}} \mathrm{k}_{\mathrm{t}}
$$

for different values of $\left(\beta_{\mathrm{a}}, \beta_{\mathrm{k}}\right)$, and then using a nonlinear search routine to find that value of this parameter vector that minimized the sum of square residuals from this regression. 
Again the results presented here use the bias reducing kernels in Bierens (1987) (though we have also used a standard normal kernel with little difference in the resulting coefficient estimates). 14

Finally the results indicated that a linear trend (representing disembodied technical change) was significant, so we included a time trend in the production function in (10), and carried it through the entire estimation procedure.

A note on the properties of these estimators is in order before proceeding. Pakes and Olley (1991) provide a set of conditions on $h_{t}(\cdot), P_{t}(\cdot), g(\cdot)$, and the distribution of the data, that insure that when we use the kernel estimator of $g(\cdot)$ in equation (13) we obtain consistent and asymptotically normal estimators of the capital age and time coefficients (it adapts and extends previous results by Newey 1991b, and Andrews 1990b to cover problems which require estimates of nonparametric functions which are indexed by either other nonparametric functions, or by the parameters of interest). Appendix 2 of this paper uses the results in Pakes and Olley (1991) to obtain a formula for a consistent estimator of the covariance matrix of our parameters. We do not currently know of a theorem that insures consistency and asymptotic normality when the series estimator is used for $g(\cdot)$ in equation (13). On the other hand, we would find it surprising if the series estimator did not have the same properties as the kernel estimator, and it is much easier to compute.

The results of the alternative three step estimation procedures, together with some other estimates of the production function coefficients, are provided in table 6. Columns 1 and 2 obtain their estimates from the subset of the data that contains only those plants that were active throughout the entire sample period. That is, these columns use the

14The estimation procedure here was computationally more burdensome as the kernel had to be re-evaluated each time we needed to evaluate the objective function at a different parameter vector. As a result we chose the bandwidth by cross validation at the estimate of the parameter vector obtained from the series estimation procedure, and held the bandwidth fixed at that value thereafter. 


\begin{tabular}{|c|c|c|c|c|c|c|c|c|c|c|c|c|}
\hline \multirow{11}{*}{ 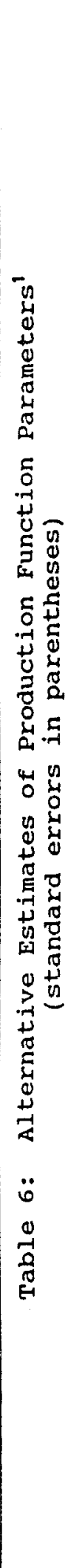 } & \multirow{11}{*}{$\begin{array}{l} \\
\\
\end{array}$} & \multirow{2}{*}{\multicolumn{2}{|c|}{ 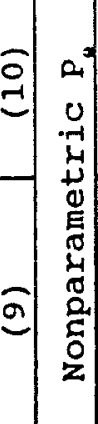 }} & $\underset{\square}{\mathscr{d}}$ & $\begin{array}{cc}n & \widehat{N} \\
6 & 0 \\
0 & 0 \\
0 & 0\end{array}$ & 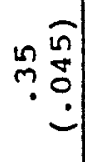 & 亲 & $\begin{array}{l}\widehat{\infty} \\
0 \\
0 \\
0 \\
0 \\
\dot{0}\end{array}$ & 1 & 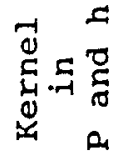 & $\ddot{n}$ & $\begin{array}{c}0 \\
0 \\
0 \\
0 \\
-1\end{array}$ \\
\hline & & & & 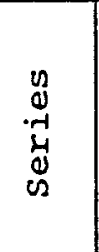 & \multirow{4}{*}{ 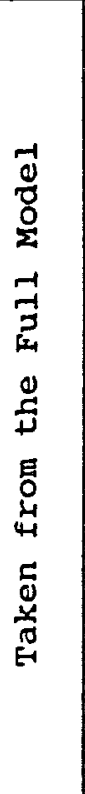 } & ঙี & $\begin{array}{l}\circ \\
8 \\
0\end{array}$ & $\begin{array}{ll}n & 0 \\
0 & -1 \\
0 & 0 \\
0 & 0\end{array}$ & 1 & 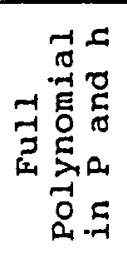 & $\begin{array}{l}\infty \\
\dot{0} \\
0 \\
0 \\
n\end{array}$ & $\begin{array}{l}m \\
0 \\
0 \\
-1\end{array}$ \\
\hline & & \multirow{3}{*}{$\begin{array}{l}0 \\
0 \\
0 \\
0 \\
0 \\
0\end{array}$} & & $\begin{array}{l}\vec{\pi} \\
\mathbb{E}_{0}^{2} \\
0_{2}^{2} \\
z\end{array}$ & & $\begin{array}{l}\text { พ } \\
\text { مิ } \\
\text { บ. }\end{array}$ & $\begin{array}{l}\text { ñ } \\
\text { No } \\
\text { o } \\
0 . \\
i \stackrel{0}{0}\end{array}$ & 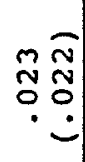 & 1 & 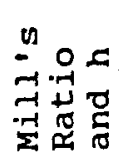 & م. & $\begin{array}{c}0 \\
0 \\
0 \\
-1\end{array}$ \\
\hline & & & & $\begin{array}{l}\Sigma \\
27 \\
\\
5\end{array}$ & & $\stackrel{0}{\stackrel{\tilde{o}}{0}}$ & $\begin{array}{l}10 \\
0 \\
0 \\
0 \\
0\end{array}$ & 농 & I & $\begin{array}{l}0 \\
\stackrel{4}{0}= \\
3 \\
0 \\
0 \\
0\end{array}$ & $\begin{array}{l}\infty \\
\dot{0} \\
\infty \\
\infty \\
i n\end{array}$ & $\begin{array}{l}0 \\
0 \\
0 \\
-1\end{array}$ \\
\hline & & & & 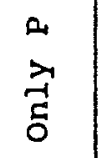 & & 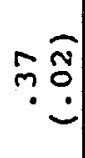 & $\begin{array}{l}0 \hat{\tilde{N}} \\
\stackrel{0}{0} \\
i \stackrel{0}{0}\end{array}$ & m. & 1 & $\begin{array}{l}0 \\
4 \\
0 \\
0 \\
3 \\
0 \\
0 \\
0\end{array}$ & $\begin{array}{l}0 \\
\dot{9} \\
\sigma \\
\sigma\end{array}$ & $\begin{array}{l}0 \\
0 \\
0 \\
-1\end{array}$ \\
\hline & & $\sqrt{10}$ & & 3 & $\begin{array}{ll}\tilde{0} & \widehat{0} \\
0 & 0\end{array}$ & \begin{tabular}{l}
$\stackrel{M}{\Im}$ \\
\hdashline \\
\hdashline
\end{tabular} & $\begin{array}{l}\text { No } \\
0 \\
0 \\
0 \\
i\end{array}$ & \%马 & $\stackrel{9}{\because}$ & 1 & 1 & 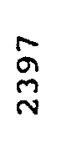 \\
\hline & & \pm & & $\begin{array}{c}5 \\
\stackrel{-1}{5} \\
\underset{4}{-1} \\
3\end{array}$ & 绐 & 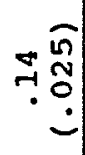 & 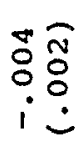 & $\begin{array}{l}\text { जู } \widehat{n} \\
0 \\
0\end{array}$ & & & & 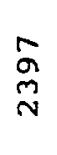 \\
\hline & & $\overline{\mathrm{m}}$ & & 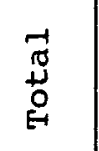 & $\begin{array}{ll}n & \overline{9} \\
0 & 0 \\
0 & 0 \\
0\end{array}$ & 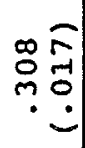 & 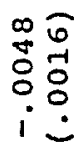 & 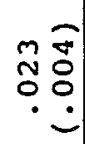 & 1 & 1 & 1 & 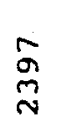 \\
\hline & & $\widehat{N}$ & & 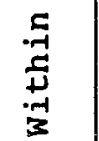 & \begin{tabular}{ll}
$m$ & 0 \\
& 0 \\
\hdashline & 0 \\
$\ddots$ & 0
\end{tabular} & 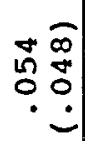 & $\begin{array}{ll}0 & 0 \\
-1 & -1 \\
0 & 0 \\
1 & 0\end{array}$ & $\begin{array}{ll}r & \widehat{0} \\
\vec{J} & -1 \\
0 & 0 \\
0\end{array}$ & 1 & 1 & 18 & $\begin{array}{l}0 \\
\infty \\
\infty\end{array}$ \\
\hline & & $\overline{-1}$ & & $\begin{array}{l}\overrightarrow{1} \\
\stackrel{5}{5} \\
0 \\
\stackrel{0}{*}\end{array}$ & $\begin{array}{ll}0 & 0 \\
0 & 0 \\
0 & 0 \\
0 & 0\end{array}$ & 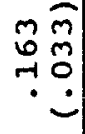 & $\begin{array}{l}-10 \\
0 \\
0\end{array}$ & $\begin{array}{l}n \widehat{0} \\
\stackrel{0}{0} \\
0 \\
0\end{array}$ & 1 & 1 & 1 & $\begin{array}{l}\infty \\
\infty \\
\infty\end{array}$ \\
\hline & & & & 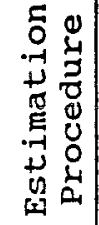 & 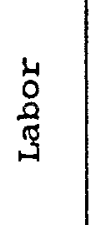 & 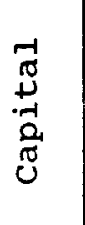 & $\varliminf_{<}^{\infty}$ & $\underset{\Theta}{\stackrel{\mathscr{O}}{E}}$ & 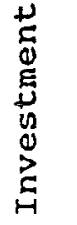 & 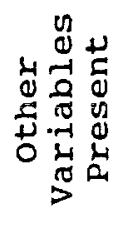 & 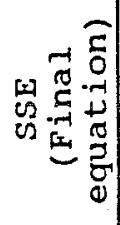 & $\begin{array}{l}\sim \\
0 \\
0 \\
0\end{array}$ \\
\hline
\end{tabular}




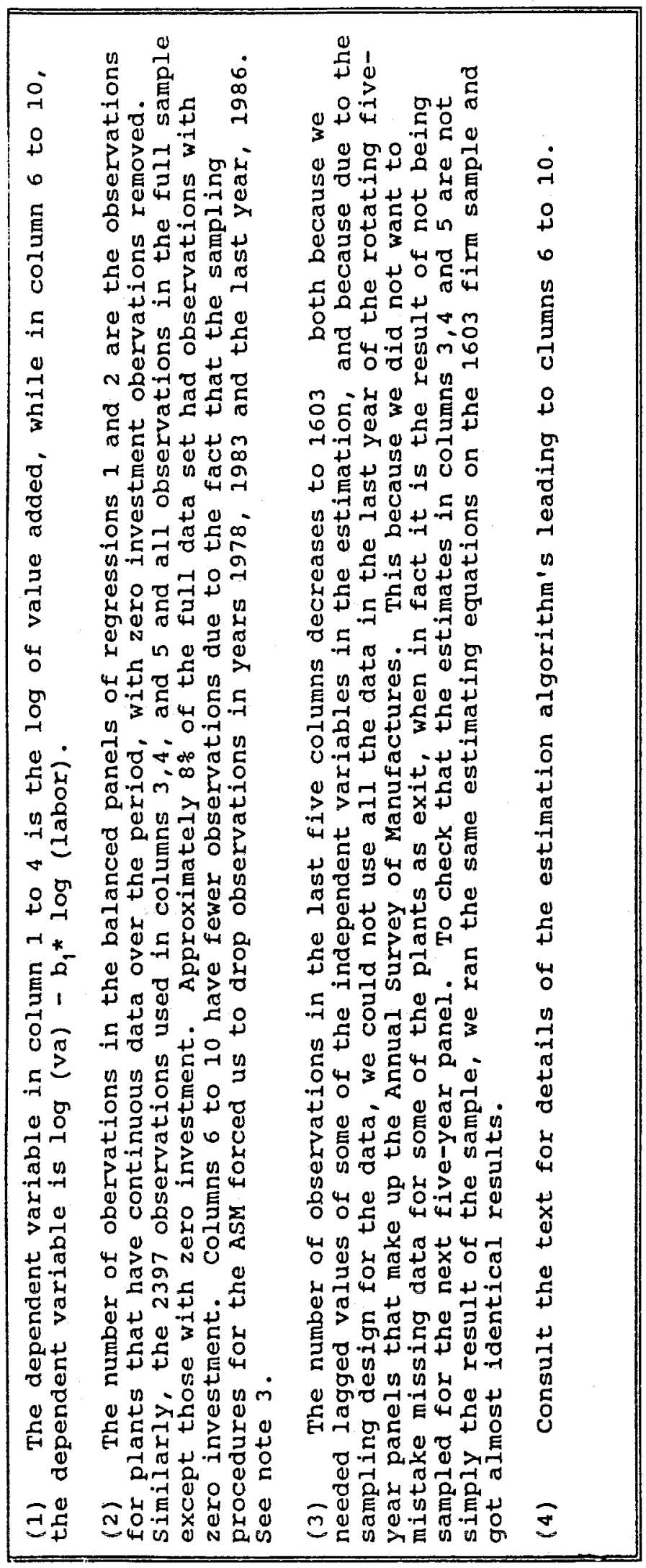


traditional "balanced" panel. Column 1 provides the O.L.S. estimates from the balanced panel, while column 2 provides the within estimates (the estimates from a fixed effects model which uses deviations from plant specific means as data in a least squares estimation procedure). Columns 3 to 10 use the "full" sample; this sample keeps plants that eventually drop out for all periods in which they are active, and introduces new entrants as they appear. Column 3 provides the O.L.S. estimates from the full sample, column 4 provides the within estimates, and column 5 adds investment to the right hand side variables and reruns the O.L.S. procedure. Columns 6 and 7 make partial corrections to the O.L.S. procedure (the first for selection, and the second for the serially correlated unobserved state variable; see below). Columns 8 to 10 provide different versions of our three step estimation procedure.

The first point to note from the table is that the full sample contains over two and a half times the number of observations in the balanced panel. That is, the selection criteria that is implicit in using a balanced panel throws out 60 to 70 percent of the observations in the full sample. The fact that these fractions are so large, together with the theoretical discussion which implied that the selection process should generate very particular biases in the estimates of the production function coefficients, will help clarify some of the anomalies generated by the balanced panel.

The estimates in columns (1) and (2) are what we have come to expect from production function estimates from balanced panels. The labor coefficient is higher than what we expect for the elasticity of output with respect to labor (certainly higher than the share of labor in total cost which is about .65 in this data), while the capital coefficient is lower than what we would expect (it almost disappears in estimates which use the "within" dimension, see column 2). 15

15We will not focus on either the age or the time coefficients in what follows since, though their values are generally consistent with our expectations, they are never estimated with much precision. 
Recall that we had two reasons for worrying about biases in these estimates. First endogeneity of the input choices should lead to a positive correlation between the inputs and the unobserved productivity term (a problem which is likely to be more severe the more variable the input and hence the easier it is to adjust the input to current realizations of productivity). This is the traditional reason for believing there is a positive bias in the ordinary least squares estimate of the labor coefficient. The within estimator will only account for the bias to the extent that the plant's productivity term is constant over time (and recall that this is an industry that underwent a major restructuring during the period under study). Second, even considering the 1972 cross section as the universe for the subsequent analysis, by taking the balanced panel we are keeping only those firms who did well enough to survive the entire period (recall that Table 4 indicated that this was under a half of the plants that were active in 1972). Since firms with larger capital stocks will survive on the basis of lower productivity realizations, selecting on survival generates a negative correlation between the disturbance term in the selected sample and capital.

By going to the full sample we expect to eliminate much of the selection problem, but not necessarily the problems generated by the endogeneity of input choices. Columns 3 and 4 provide the O.I.S. and within estimates on the full sample. The simple act of adding back in the plants that were active during only part of the sample period almost doubles the capital coefficient and pushes the labor coefficient down by about $20 \%$ (and this is true whether we compare the total or the within columns). Of course, both the column 3 and 4 coefficients should still be biased by both selection and endogeneity. In particular since the within column uses only changes over time and has to discard those plant-year changes in productivity that induce the plant to close down, one might expect it still to contain a large negative bias in the capital coefficient generated by selection; whereas the total column makes no attempt at all to control for firm specific differences in productivity, so we might expect it still to contain a large positive bias in the labor coefficient.

More formally, to account for the positive bias in the labor coefficient in column 3, 
we need to substitute a polynomial expansion in the triple $\left(i_{t}, a_{t}, k_{t}\right)$ for $w_{t}$ in equation 10 and to reestimate that equation. Column 5 adds only investment to the list of regressors in column 3. If the polynomial needed for $w_{t}$ were both linear and did not require interactions with time for the different regulatory periods, the estimate of the labor coefficient in column 5 would be consistent. The capital and age coefficients, however, would confound the effect of capital and age on output with their effects on investment and hence have no direct interpretation. There are two points to note from the estimates in column 5 . First the investment coefficient is highly significant, indicating that there is indeed likely to be a simultaneiry bias in the estimates of column 3. Second, as predicted by the theory, the labor coefficient goes down again, this time by another $10 \%$.

The labor coefficient from equation (10), the equation that used a fourth order polynomial expansion in $\left(i_{t}, a_{t}, k_{t}\right)$ whose coefficients were allowed to vary over the four regulatory periods to account for $v_{t}$, was $.615(.027)$ (not very different from the coefficient from column 5 , and between 10 and $15 \%$ lower than the O.L.S. coefifient on the full sample). Columns 6 to 10 use this coefficient, the implied estimate of $w_{t}$, and the estimate of $\mathscr{P}_{\mathrm{t}}$ from the selection equation [(11)], to obtain estimates of the capital, age, and time coefficients.

Column 6 regresses $y_{t+1}-.615 l_{t+1}$ on age, capital, and a polynomial in the estimate of the selection probability. If there were no serial correlation in $w_{t}$, implying no endogeneity problem in this equation, use of the polynomial in the estimated selection probability should correct for the selectivity bias and generate consistent estimates of the coefficients of interest. On the other hand, if $\omega$ is serially correlated, then we would expect $k_{t+1}$ to be positively correlated with $w_{t}$, producing a positive bias in the capital coefficient in this column. So we would expect this column to provide us with an estimate of an upper bound to the capital coefficient.

Column 7 regresses $y_{t+1}-.615 l_{t+1}$ on age, capital, and a polynomial in $\hat{h}_{t}$, the estimate of $v_{t}$ that we obtain from the first equation. If firms could not exit, so that there 
were no selectivity problem, then use of the polynomial in $\hat{h}_{t}$ would correct for the endogeneity problem and produce consistent estimates of the coefficients of interest. Given that even transitions on the full panel are selected for survival (though this is only survival over a two, and not a thirteen, year period), and that theory tells us that the selection process should generate a negative bias in the capital coefficient, we expect this column to provide an estimate of a lower bound for the capital coefficient.

The estimates of the upper and lower bounds were, respectively, $.37(.02)$ and .29 (.03) (the standard errors of the coefficients in these columns were obtained from a bootstrap procedure). The implied interval rules out both balanced panel estimates and the within estimates from the full sample, but still leaves a fairly large range of possible values for the true capital coefficient. Note also that the fact that the value of the minimand in column 7 is much lower than that in column 6 attests to the likely empirical importance of the serially correlated unobserved state variable that $\hat{h}_{t}$ proxies for.

Column 8 provides a halfway mark between the generality of our full model and a parametric alternative. The consistency of the estimates in this column require that $\mathbb{P}_{\omega}$ be given by the parametric family

$$
w_{t+1}=\rho v_{t}+\xi_{t+1} \text {, where } \xi_{t+1} \sim N(0, \sigma)
$$

and $N()$ signifies a normal distribution. Briefly, it uses the probit estimates of the selection equation to obtain a nonparametric estimate of the truncation point in that equation and then notes that, given the normality assumptions, the expectation of $\omega_{t+1}$ conditional on past history and survival will depend only on $\omega_{t}$ (estimated by $\hat{h}_{t}$ ) and Mill's ratio evaluated at the truncation point. Columns 9 and 10 provide the series and the kernel estimates of the version of our model which does not restrict $\mathbb{P}_{4}$.

The first point to note is that all three of these procedures produce estimates of capital coefficients that are between the upper and lower "bounds" for this coefficient given 
in columns 6 and 7 . There is some evidence that the constraint imposed by normality produces both a lower capital coefficient and a significantly worse fit than the more general model, so we shall disregard column 8 in what follows. The other two estimates are not much different from one another; and this is true whether we use as our difference metric their estimated standard errors or their empirical implications as discussed in the next section (we have actually done the empirical analysis using both the column 9 and the column 10 estimates with no significant difference in results). ${ }^{18}$ On the other hand both columns are quite different from the results of the more traditional estimation procedures discussed earlier.

\section{The Implications of Our Estimators on Productivity}

This section of the paper uses our production function estimates to construct measures of plant level productivity in the telecommunications equipment industry and then analyzes changes in the distribution of this productivity measure between 1974 and 1987 . Our plant level productivity measure is calculated as

$$
p_{i t}=y_{i t}-b_{\ell} \ell_{i t}-b_{k} k_{i t}-b_{a} a_{i t}
$$

${ }^{16}$ We have done alot more analysis of these coefficients than is reported above, and this note reviews the other results. The system was estimated using several different estimators for the nonparametric components, and adding a trimming step to account for obseryations in low density regions. None of the alternate estimators generated much of a change in the coefficient estimates (the capital, age, and time coefficients varied between .31 and .35 , -.01 and .01 , and .01 and .04 respectively). There was one run, however, in which the estimated standard errors doubled as a result of an outlier that was trimmed in the trimming procedure. In addition we ran systems in which multiplant firms had different investment and stopping rules (we also tried differentiating by the number of plants), and investigated differences in estimates over different subperiods of the panel. The only significant (from a statistical point of view) change occured when we split the sample into three equally sized time intervals, and reestimated the model on the first and last of these. The results provided evidence of an increase in the capital intensity of the industry over time, as the O.L.S.capital coefficient from the full subsamples went from $.27(.03)$ to $.34(.03)$, and the estimates from the bias reducing kernel version of our procedure went from $.32(.08)$ to $.40(.05)$. Again these differences are simply not large enough to make any substantial difference to the economic implications discussed in the next section. 
where the b's are taken from column 10 in table 6.

We begin with aggregate industry productivity. Table 7 compares two measures of aggregate industry productivity growth between 1975 and 1987. We calculate our aggregate measure ( $\mathrm{P} 1$ in the first column) as the share-weighted average of our plant level productivity measure, using the plant level shares in the full sample as weights. P2 in column 2 provides the productivity growth rates derived in an analogous way but using the production function coefficient estimates and the shares of output from the balanced panel (from column 1 in Table 6). Column 3 sums the difference between P1 and P2 from the beginning of the sample period, while column 4 provides the BLS's measure of growth in aggregate manufacturing productivity (P3). Figure 1 normalizes productivity to equal 1 in 1974 , and then plots the levels of our measure, and of the measure obtained from the balanced panel, over the period. The difference between the two curves in this figure is column 3 of table 7 .

We begin with a comparison of P1 to P2. Column 3 makes it clear that P1 drops below $\mathrm{P} 2$ immediately and remains below it throughout the sample period. Indeed tile average annual growth rate of P2 (1.68\%) over the period as a whole is over double the growth rate of P1 (.78\%). Recalling that the balanced panel excludes those plants which exit during the sample period, a selection which our theory tells us should delete precisely those plants with low productivity growth, the fact that P1 is lower than P2 should not be surprising. The other difference between the two samples is that the balanced panel excludes new entrants. Empirically new entrants tended to be smaller plants with lower productivity than the average productivity of continuing establishments (but higher productivities than those plants who exit). So the difference in the treatment of new entrants between the two panels reinforces the difference between the productivity measures that is induced by the difference in the treatment of those who exit.

Note that this reasoning leads us to expect particularly large differences between the productivity measures in periods when there is disproportionate amounts of entry and exit. 


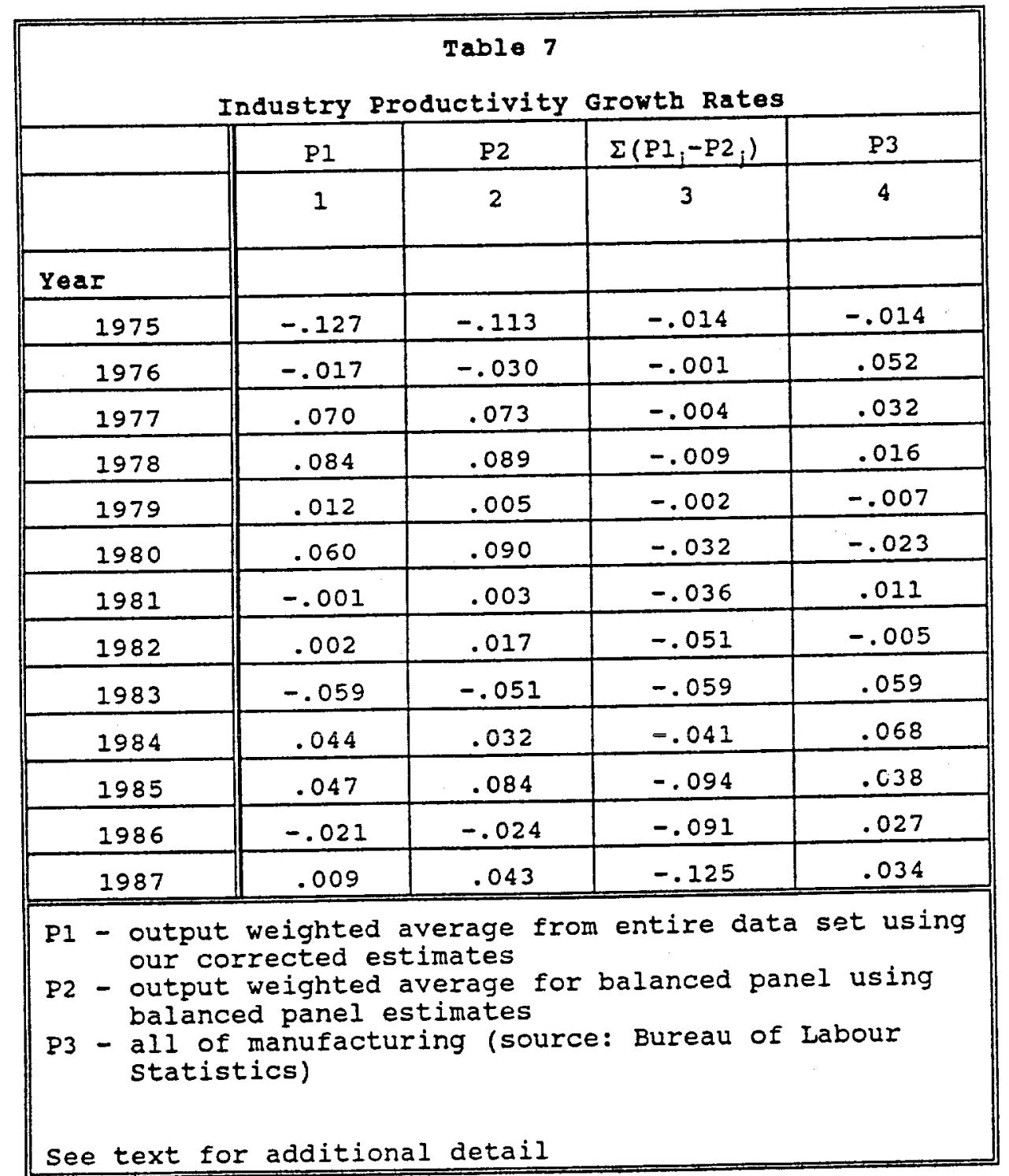




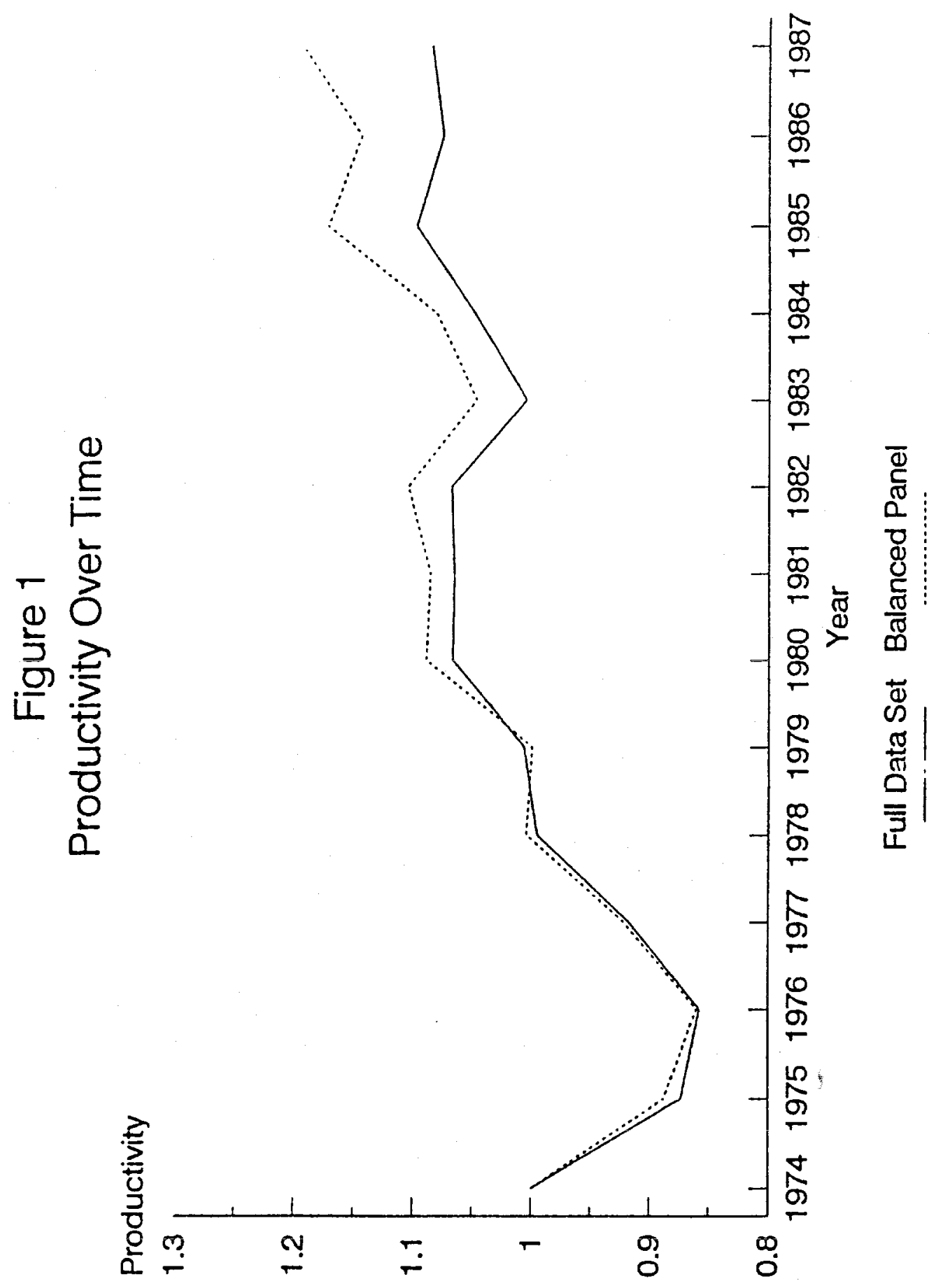


Column 3 shows that the difference between $\mathrm{P} 1$ and $\mathrm{P} 2$ takes a jump upward in about 1980 , just after the certification and registration program, and then another discrete jump in 1985, just after divestiture. These were precisely the years where there was likely to be disproportionate amounts of entry and exit (see tables 3 and 4 above, and table 11 below). Indeed the average annual difference between $\mathrm{P} 1$ and $\mathrm{P} 2$ in the period after divestiture was $2.2 \%$ (3.4\% versus $1.2 \%$ ), almost two and a half times the average annual difference between $\mathrm{P} 1$ and $\mathrm{P} 2$ over the entire sample period. The lesson here is that aggregate productivity calculations based on balanced panels can generate large positive biases during periods when an industry is undergoing a significant amount of restructuring.

The extent to which the movements in $\mathrm{P} 1$ can be accounted for by the historical changes in the structure of the telecommunications equipment industry is quite striking. Notice first the surges in productivity that follow both the registration and certification program in 1977 and 1978 , and the divestiture in 1984 . Also the growth rate in productivity is practically zero in 1982 and negative from 1982 to 1983. Given that the Consent Decree announcing divestiture was signed in January 1982, this period was undoubtedly a time of reorganization and restructuring for the industry as a whole. The negative growth in productivity probably reflects the cost of reorganization among incumbents and the time it takes new entrants to settle into production.

Column 4 provides annual growth rates in productivity for all of manufacturing. Note that the two periods of high growth rates in the telecommunication equipment industry, 1976-77 and 1984-85, are not reflected in the data on aggregate manufacturing. The two periods of telecommunications productivity growth are a result of factors that are specific to that industry (eg., regulatory changes) and are not related to trends in overall manufacturing. This comes through even more clearly in Table 8 , where we provide the correlation coefficients between the three growth rate series in Table 7. The growth rate of productivity in the telecommunication equipment industry has an $\mathrm{r}^{2}$ of almost zero with the growth rate for manufacturing as a whole. 


\begin{tabular}{|c|c|c|c|}
\hline \multicolumn{4}{|c|}{ Table 8} \\
$\begin{array}{r}r^{2} \text { 's for the Growth Rates reported in } \\
\text { Table 7 }\end{array}$ \\
\hline & P1 & P2 & P3 \\
\hline & & & \\
\hline P1 & 1.00 & .916 & .008 \\
\hline P2 & .916 & 1.00 & .001 \\
\hline P3 & .008 & .001 & 1.00 \\
\hline
\end{tabular}


We now delve deeper into the determinants of industry productivity. We first ask about the efficiency of the output allocation among plants in the industry. One can ask this question either conditional on the extant distribution of fixed factors (age, capital, and productivity) or unconditionally. We begin by considering the efficiency of the allocation conditional on the distribution of fixed factors. To analyze this issue, we introduce a variable cost efficiency index. The index is defined as the ratio of the minimum variable cost of producing industry output, given the current distribution of fixed factors (capital, age, and productivity), to the actual variable cost of producing industry output. Firms are assumed to minimize variable cost given their fixed factors, so their actual variable cost of production is calculated as

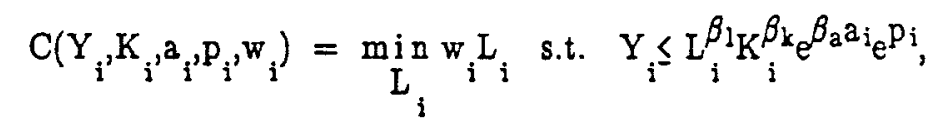

where $p_{j}$ is productivity as defined at the beginning of this section. The minimum total variable cost of producing industry output is calculated as the solution to

(16) $\quad Y_{i}, \ldots, Y_{N} \sum_{i=1}^{\min } C\left(Y_{i}, K_{i}, a_{i}, P_{i}, w_{i}\right)$ s.t. $\sum_{i=1}^{N} Y_{i}=Y$.

The static efficiency index is calculated as the ratio of (16) to the sum of (15) across plants. The results from this calculation are presented in Table 9 where we have averaged the annual static cost efficiency index over several sub-periods.

Table 9 actually goes one step further than this. It decomposes the static variable cost efficiency index into a product of two terms; a term providing a measure of the efficiency of the allocation of output among plants within a firm (the intra firm index), and a term providing a measure of the efficiency of the allocation of output between firms (the inter firm index). Specifically the intra firm index is the ratio of the variable cost of 


\begin{tabular}{|c|c|c|c|}
\hline \multicolumn{4}{|c|}{$\begin{array}{l}\text { Table } 9 \\
\text { tatic Cost Efficiency } \\
\text { cost of production divided } \\
\text { ctual cost of production) }\end{array}$} \\
\hline Years & Total & Interfirm & Intrafirm \\
\hline $1974-1977$ & .77 & .85 & .91 \\
\hline $1978-1983$ & .67 & .74 & .91 \\
\hline $1984-1986$ & .71 & .80 & .89 \\
\hline Mean & .72 & .80 & .90 \\
\hline
\end{tabular}


production one would obtain if one allocated the actual firms' outputs efficiently among their own plants to the actual cost of production (obtained from 15). The inter firm component is the ratio of the minimum cost of production obtained from (16) to the cost of production obtained by efficiently allocating the existing firm distribution of output among the plants in the alternative firms (to the numerator of the intra firm index). Thus the product of the inter firm and the intra firm indices must equal the total index.

The total column of Table 9 shows that, not surprisingly, the static efficiency index declined in the 1978-83 period, the period when the industry was undergoing the restructuring induced by the Consent Decree. It did increase again after deregulation, but not to the level it had achieved in the pre 1978 period. All the movements in the static efficiency index are caused by movements in the inter firm component of the index, the intra firm component was essentially constant at the high level of .9 throughout the period.

The more competitive structure that emerged after deregulation seems to have generated an inter firm allocation of output that is less efficient, conditional on both the total output produced by the industry and on the existing joint distribution of fixed variables, than the output allocation prior to deregulation. The lesson here is that more concentrated industry structures may well allocate output among existing plants in a more cost effective manner. The benefits from competition come from either less restrictive output practices, a reallocation of fixed factors towards more productive enterprises, or increases in average productivity growth. We now turn to an investigation of the latter two possibilities.

Recall that while the static variable cost efficiency index seems to have fallen after deregulation, the aggregate industry productivity figures increased following both periods of regulatory change. To see what is behind this set of results it is helpful to decompose the productivity figures in a slightly different way. Recall that our measure of industry productivity is a weighted average of plant level productivity, with shares of industry 
output used as weights, i.e.

$$
p_{t}=\sum_{i=1}^{N} s_{i t}^{N_{i t}} p_{i t}
$$

where $p_{t}$ is industry productivity at time $t, p_{i t}$ is plant level productivity, and $s_{i t}$ is plant i's share of output at time $t$. Now decompose $p_{t}$ into a sum of two terms as follows

$$
\begin{aligned}
p_{t} & =\sum_{i=1}^{N_{t}}\left(\vec{s}_{t}+\Delta s_{i t}\right)\left(\bar{p}_{t}+\Delta p_{i t}\right) \\
& =N_{t} \bar{s}_{t} \bar{p}_{t}+\sum_{i=1}^{N_{i t}^{t}} \Delta s_{i t} \Delta p_{i t} \\
& =\bar{p}_{t}+\sum_{i=1}^{N-s_{t}} \Delta s_{i t} \Delta p_{i t}
\end{aligned}
$$

where

$$
\Delta s_{i t}=s_{i t}-\bar{s}_{t} \text {, and } \Delta p_{i t}=p_{i t}-\bar{p}_{t^{\prime}}
$$

and $\bar{p}_{t}$ and $\bar{s}_{t}$ represent the unweighted mean productivity and the unweighted mean share, Iespectively.

Table 10 presents data on the three terms from equation (18). Column 1 is the left hand side of the equation; industry productivity constructed as a weighted average of plant-level productivities. Column 2 provides the unweighted average of plant level 


\begin{tabular}{|c|c|c|c|c|}
\hline \multicolumn{5}{|c|}{ Table 10} \\
\hline & 1 & 2 & 3 & 4 \\
\hline Variable & $p_{1}$ & P. & $\Sigma \Delta p_{i,} \Delta s_{i f}$ & $\operatorname{corr}\left(p_{i-1}, k_{i r}\right)$ \\
\hline \multicolumn{5}{|l|}{ Year } \\
\hline 1974 & 1.00 & .91 & .09 & -.059 \\
\hline 1975 & .87 & .81 & .07 & -.092 \\
\hline 1976 & .86 & .78 & .08 & -.106 \\
\hline 1977 & .92 & .86 & .06 & -.070 \\
\hline 1978 & 1.00 & .91 & .09 & -.036 \\
\hline 1979 & 1.01 & .96 & .05 & -.030 \\
\hline 1980 & 1.07 & .96 & .11 & -.008 \\
\hline 1981 & 1.07 & .90 & .17 & .037 \\
\hline 1982 & 1.07 & .93 & .14 & .010 \\
\hline 1983 & 1.00 & .92 & .09 & -.056 \\
\hline 1984 & 1.05 & .97 & .08 & -.072 \\
\hline 1985 & 1.10 & .89 & .21 & .036 \\
\hline 1986 & 1.08 & .90 & .17 & .050 \\
\hline 1987 & 1.08 & .86 & .23 & .120 \\
\hline
\end{tabular}


productivity, i.e. $\bar{p}_{t}$. Column 3 provides the second term on the right hand side of (18), the sample covariance between productivity and output. The larger this covariance, the higher the share of output that goes to more productive firms and the larger is industry productivity. Finally, the fourth column of Table 10 gives the correlation coefficient between plant-level capital and plant-level productivity.

The table helps separate out the factors underlying the increase in productivity in column 1. $\bar{p}_{t}$ has not changed all that much since 1979, but there has been a reallocation of output from less to more productive plants. It is this reallocation of output, and not any increase in average productivity, that is driving the increase in productivity at the industry level. From the analysis of the static efficiency index above, we know that this reallocation of output to more productive plants is not a result of a more efficient allocation of variable factors of production conditional on the existing distribution of fixed factors. So it should be a result of a reallocation of capital towards the more productive plants. A complete analysis of precisely how this happened and of the effects of various policy and environmental changes on that process would require us to fill in the details of the dynamic general equilibrium model that lay behind the adjustment process that occurred in this industry - a task beyond the scope of this paper. We can, however, provide some reduced form evidence on the importance and implications of the capital reallocation process.

Column 4 of Table 10 provides the correlation between capital and productivity. It has increased dramatically since the Consent Decree, and it increased substantially following the earlier regulatory changes also. In fact the only two years in which there was a perceptible drop in the capital-productivity correlation were $1983 / 84$, the years when the adjustment to deregulation must have been greatest.

One can also see the impact of the reallocation of capital towards more productive firms in the analysis of exit behavior. The stopping rule that comes out of the dynamic behavioral model (equation 5) implies that whether or not a firm shuts down is a function of its productivity, capital stock, and age. The nonparametric estimation procedure uses 
this fact to derive the survival probabilities, but treats these probabilities as nuisance parameters, never examining them for their independent economic interest. Table 11 provides a simple probit analysis of survival probabilities with our estimates of productivity, capital, and age, as well as time dummies, as right hand side variables. The probits have the exit probability negatively related to both the firm's capital stock, and to the firm's productivity (though, as in the production function, age is insignificant and sometimes of the wrong sign), with productivity being the most significant of the two variables. Also, there seems to be a clear effect of deregulation on the probability of exit. Conditional on any triple for the state variables, that probability seems to have gone up after 1980. So one mechanism for the reallocation of capital that facilitated the increase in aggregate productivity that accompanied deregulation seems to have been an increase in the rate of shutdown of unproductive plants.

Our results indicate that the changes that occurred in the telecommunications industry in this period improved the performance of the telecommunications equipment industry by inducing a reallocation of capital from less to more productive plants. Note that since this reallocation process seems to be greatly facilitated by entry and exit, an important part of it would not be picked up from the analysis of balanced panels (much less from aggregate data). Nevertheless, it is this reallocation of capital, rather than some increase in either the efficiency of the allocation of variable inputs, or in average productivity, that seems to be behind the increase in productivity that followed the deregulation of the telecommunications equipment industry.

\section{Concluding Caveats.}

We conclude with two related caveats. First we would like to emphasize that it is still too early to assess the full impact of deregulation on productivity in the telecommunications equipment industry. Our analysis suggests that the change in regulatory structure was followed by an increase in industry productivity generated by a 


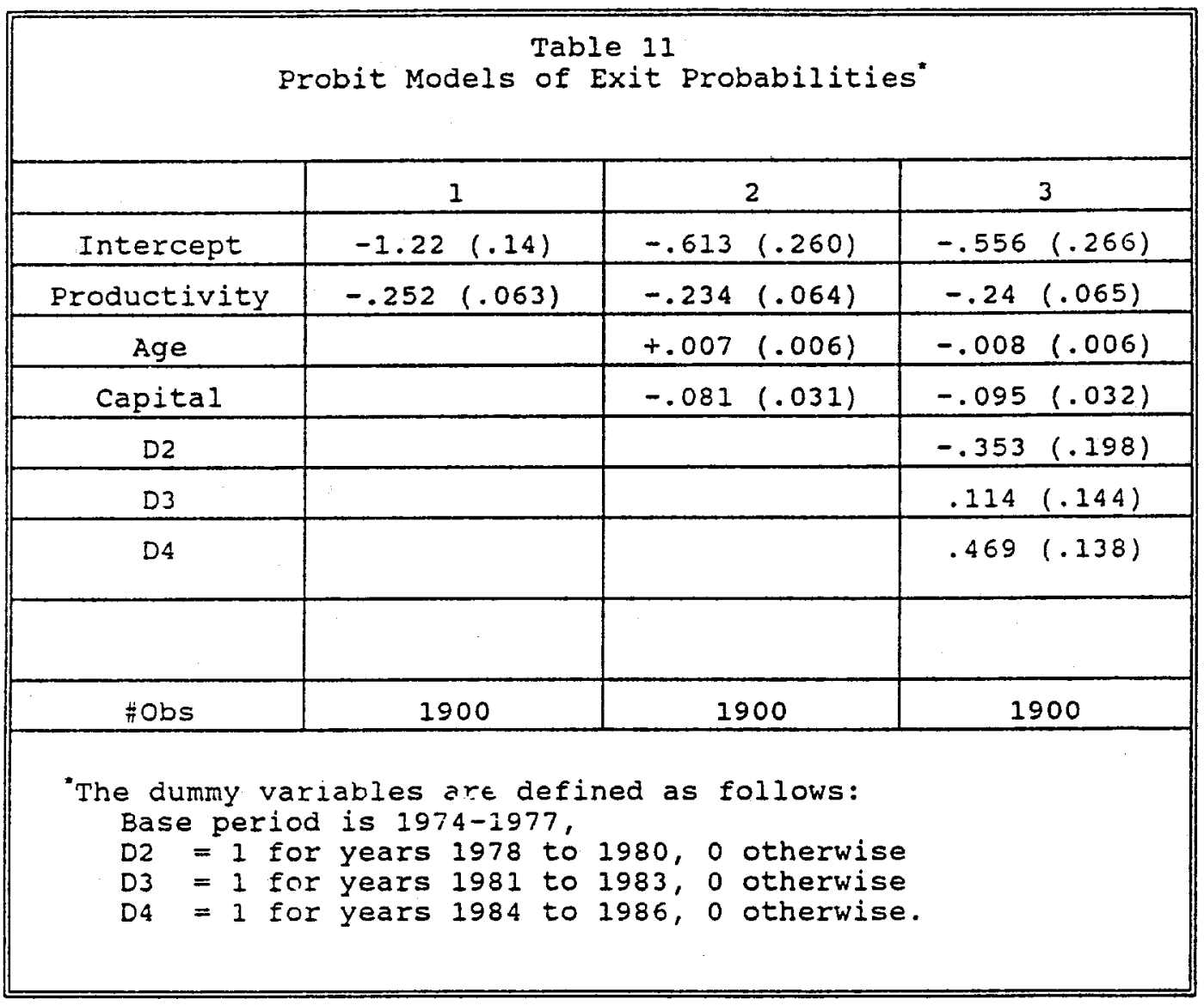


reallocation of capital and a shift in production towards more productive plants.' However the long term question of the effect of the divestiture on productivity will also have to come to terms with its effect on R\&D activity. Partly as a result of the tremendous success of research efforts at Bell Labs, the telecommunications network in the United States is the most sophisticated network in the world. Our estimates indicate that there has not been an increase in average productivity since divestiture. However any change in productivity that resulted from a change in the structure of $R \& D$ in the industry after deregulation would probably not manifest itself in the data until after 1987 . On this point we should note that when we take the RBOC's together with AT\&T there joint R\&D expenditures and employment after divestiture are not lower than the predivestiture levels of AT\&T (Noll,1987). On the other hand it is still too early to know how the change in the structure of the industry has affected the productivity of those $R \& D$ expenditures.

The second point is related, though more theoretical. What seems to be clear from the data is that certain enterprises generate more sales for given amounts of capital and labor expenditures than others, and that differences in this sales generating ability (which we call productivity) among plants are highly correlated over time. This implies that there is an unobserved, serially correlated, state variable that is a determinant of both survival probabilities and input choices.

The way the model of sections II and III deals with this unobserved, serially correlated, state variable is to assume that there is 1 one to one relationship between it and investment conditional on the observed state variables of the problem (at least on the subset of the data with $i_{t}>0$ ). A more general model than the one outlined here, say one that allowed for a separate effect of the outcome of an R\&D process on profits, and hence on the investment decision, would be unlikely to generate such an invertibility condition without incorporating information on additional observables. We stopped where we did because of a combination of data availability and the fact that the framework presented here seemed rich enough to capture the nature of the restructuring that occurred in the 
telecommunications equipment industry during the period of our study. We do not doubt, however, that extensions to (or modifications of) our techniques may be necessary in order to come to grips with either different questions or different data sets.

The conceptual point we would like to emphasize is not that our solution ought always to be used. Rather it is that the solution that is used to study changes in the performance of an industry should take into account the fact that different enterprises are differentially efficient in producing sales, and that though these efficiency differences do vary over time, they are highly serially correlated. A result of this serial correlation is that the efficiency differences themselves become determinants of the rates of expansion (or contraction) of plants. This makes them an integral part of the process by which markets adjust to changes in their environment. In our case it was differences in the extent to which this adjustment took place pre and post deregulation that was the major determinant of the pre and post deregulation differences in industry performance. 
Appendix 1. The Data.

The data used in this study is an extract drawn from the Longitudinal Research Database (LRD) maintained at the Center for Economic Studies at the Bureau of the Census. The LRD contains all the data for manufacturing establishments collected by the Census of Manufactures in 1963,1967,1972,1977, and 1982, and by the Annual Survey of Manufactures for non-Census years from 1973 to 1986 . The data is collected at the establishment level and includes detailed information on the inputs and output that characterize the production process. A more detailed description of the data and of how we constructed the variables used in this analysis can be found in Olley(1991).

Telecommunications networks are composed of three broad categories of equipment. Terminal equipment is equipment that terminates a telephone wire at a customer's premises and includes such products as telephone sets, key telephone sets, facsimile machines, and modems. Transmission equipment, which carries the signal between terminal stations and switching centers, includes coaxial cable, microwave radio equipment, optical fiber, and communications satellites. Finally, switching equipment, which is the heart of the network, links the terminals of the telecommunications system. The main types of switching equipment are private branch exchanges (PBX) and central office switching centers. This study focuses on all three types of equipment with the exception of transmission cable. Thus, we do not include plants that produce the various types of transmission media such as copper wire, coaxial cable, or glass fibers.

In terms of the classification system used by the U.S. Bureau of the Census, the telecommunications equipment industry is made up primarily of those plants that are classified in SIC industry 3661, Telephone and Telegraph Apparatus. The three 5 digit product classes within SIC 3661 are 36611 , switching and switchboard equipment, 36613 , carrier line equipment, and 36614 , other telephone and telegraph wire apparatus. This last 5-digit product class includes such products as telephone sets, key telephone sets, and 
telephone answering devices. In addition, a subset of the plants from SIC 3663, Radio and Television Communications Equipment are included in the analysis.

The subset of plants added from industry 3663 are plants that produce products within the 5-digit product class 36631 , communications systems and equipment, except broadcast. The Bureau of the Census classifies fiber optics communication equipment, microwave communication equipment, facsimile communication equipment, and carrier line equipment, n.e.c. (not elsewhere classified) in the product class 36631 , but we wished to include plants that produce these products in the analysis of the telecommunications equipment industry. However, the product class 36631 also includes military space satellites, amateur radio communications equipment, and other products that we felt should be excluded from the data set. Therefore, we had to take care to eliminate from the data set those plants that primarily produce products outside our definition of the industry.

Though our choice of product classes is as close as possible to the definition of the product market as we could get, it should be pointed out that, since we have pulled together data for plants in different four-digit SIC industries, comparison with published aggregates is limited.

We now describe the variables used in the analysis. Unless otherwise specified, all variables are measured at the plant level and are taken from the Longitudinal Research Data Base maintained at the Center for Economic Studies at the Bureau of the Census.

Value added is defined to be total shipments, adjusted for changes in inventories, minus the cost of materials. Real value added is constructed by dellating output by a 4-digit industry output deflator and dellating the cost of materials by a 4-digit materials deflator. The deflators are taken from the PCS database as extended by Wayne Gray (1989). The labor variable is an hours variable constructed by taking the total compensation for labor, including all supplemental labor costs, and dividing the total by the production worker wage rate at the given plant.

The capital measure used in the regression analysis is constructed using a perpetual 
inventory method, $K_{t+1}=(1-\delta) K_{t}+I_{t}$. Since the capital data in the LRD is detaled enough to allow one to distinguish between buildings and equipment, all calculations of the capital stock are done separately for buildings and equipment. Real capital is obtained by deflating investment by a 4-digit industry new investment deflator taken from the extended PCS data set. As suggested by Hulten and Wykopff(1981) buildings are depreciated at a rate of .0361 , and equipment at a rate of .1179 .

In order to construct the capital series using the perpetual inventory method, we had to address two other issues. We needed an initial capital stock, and we wanted to utilize the LRD data on rentals and used equipment expenditures. The method of dealing with the initial condition problem differed with the information available on the plant. If the plant was first observed in an ASM year we treated the plant as a new entry, and assumed the entire book value of capital was put in place in the previous year. If a plant is first observed in a census year, it could have opened any time between the previous census and the first observed census. As a result we calculated two estimates of capital; the first assumes that the plant is new in the observed census year, and the second assumes that the entire book value was put in place in the previous census year. The initial capital stock used in the analysis was a simple average of these two estimates. For plants first observed in the first year of the LRD (1963) we took the book value in that year as correct.

If a plant was renting capital, the rental value is capitalized and added to current year capital stock. The rental data is capitalized using rental rates for all of manufacturing supplied by the Bureau of Labor Statistics. Interestingly, rentals seem to be more important for the smaller plants than they are for the large plants. Many of the small plants do not have any buildings on their books and are renting their factory. Many of the plants also report purchases of used equipment. In the calculation of the capital stock, used equipment is deflated using the new investment deflator and added to current capital. Finally, partly because of the sampling design, there were often missing years on firms. We imputed the missing investment data by averaging the actual investment in the year just 
before the missing data with the investment in the year immediately following the gap. This allowed us to keep the historical information on the firm's capital. 


\section{Appendix 2. The Variance Covariance Matrix of the Parameter Estimates.}

This appendix provides a consistent estimator for the variance covariance matrix of the estimator of the production function coefficients. It is based on the results in Pakes and Olley (1991), which, in turn, extends previous work by Newey (1991), and Andrews(1991b). For more detail the reader should consult those articles.

Let $z$ be the vector of observables on a plant in the current and the following period (with the understanding that second period values are zero if the plant liquidated in the second year), $\mathbf{x}^{\prime}=[k, a, t]$, and $\beta^{\prime}=\left[\beta_{k}, \beta_{a}, \beta_{t}\right]$. Then, denoting second period values of a variable by a + subscript, for any estimate of $g=g\left(\mathscr{P}, \phi-x^{\prime} \beta\right), \mathscr{P}=\mathrm{P}(\mathrm{i}, \mathrm{a}, \mathrm{k})$, and $\phi=\phi(\mathrm{i}, \mathrm{a}, \mathrm{k})$, define the vector of functions

(1) $\mathrm{m}\left(\mathrm{z}, \beta, \beta_{\beta} \mathrm{g}, \mathscr{\rho}_{,} \phi\right)=\chi_{+}\left[\mathrm{y}_{+}-\beta \gamma_{+}{ }^{-\mathrm{x}}+{ }^{\prime} \beta-\mathrm{g}\left(\mathscr{\rho}, \phi-\mathrm{x}^{\prime} \beta\right)\right]\left\{-\mathrm{x}_{+}+[\partial \mathrm{g}(\mathscr{\rho}, \phi-\mathrm{x} \beta) / \partial \phi] \mathrm{x}\right\}$.

For a particular value of $\left(\beta_{p} g, \mathscr{S}_{, \phi}\right)$, say $\left(b_{p} g_{n}, \Phi_{n}, \phi_{n}\right)$, the estimation algorithm choose its estimate of $\beta$, say $b$, by minimizing $\| n^{-1} \Sigma_{j} m\left(z_{i}, b, b_{l}, g_{n}\left(\rho_{n}, \phi_{n}-x b\right) \|\right.$, where $\|x\|=x^{\prime} x$. Now if

$$
\mathrm{D}\left(\mathrm{z}, \beta, \beta_{1}, g, \mathscr{\rho}, \phi\right)=\{-\mathrm{x}++[\partial \mathrm{g}(\mathscr{I}, \phi-\mathrm{x} \beta) / \partial \phi] \mathrm{x}\}\left\{-\mathrm{x}_{+}+[\partial \mathrm{g}(\mathscr{\rho}, \phi-\mathrm{x} \beta) / \partial \phi] \mathrm{x}\right\}
$$

then it can be shown that at the true value of all of the parameters,

$$
\mathrm{D}\left(z, \beta, \beta_{,} g, \mathscr{\rho}, \phi\right)=\mathrm{E}\left[\partial \mathrm{m}(z, \beta, \beta, g, \mathscr{\rho}, \phi) / \partial \beta \mid \partial_{\mathrm{t}}, \chi_{\mathrm{t}+1}=1\right]
$$

Finally let

$$
\text { (3) } f^{*}(z, \beta, \beta, g, \mathscr{\rho}, \phi)=\mathrm{m}(z, \beta, \beta, g, \mathscr{\rho}, \phi)
$$




$$
\begin{aligned}
& +x_{+}\left\{-x_{+}+[\partial g(\rho, \phi-x \beta) / \partial \phi] x\right\}\left[y_{+}-\beta l_{+}-x_{+} \beta \beta-g\left(\rho, \phi-x^{\prime} \beta\right)\right] \\
& +x_{+}\left\{-x_{+}+[\partial g(\rho, \phi-x \beta) / \partial \phi] x\right\}[\partial g(\rho, \phi-x \beta) / \partial \rho]\left[x_{+}-\Phi\right] \\
& +x_{+}\left\{-x_{+}+[\partial g(\rho, \phi-x \beta) / \partial \phi] x\right][\partial g(\Phi, \phi-x \beta) / \partial \phi][y-\beta L \phi] \\
& +\mathscr{E}[\mathrm{y}-\beta,-\phi]\{l-E[l \mid \mathrm{i}, \mathrm{a}, \mathrm{k}]\},
\end{aligned}
$$

where $8=x_{+}{ }^{l}[\mathrm{y}-\beta+\phi] / \mathrm{E}\left\{\mathcal{L}[\mathrm{L}[\mid \mathrm{i}, \mathrm{a}, \mathrm{k}]\}^{2}\right.$.

The actual variance covariance matrix of the parameter estimates is obtained by letting $f=\stackrel{*}{f}^{*}-\mathbf{E}^{*}$, and setting

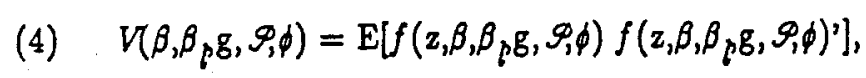

and

$$
\text { (5) } \quad D\left(\beta, \beta_{,} \mathrm{g}, \mathcal{\rho}, \phi\right)=\mathrm{E}\left[\mathrm{D}\left(\mathrm{z}, \beta, \beta_{l}, \mathrm{~g}, \mathcal{\rho}, \phi\right)\right]
$$

and then computing

$$
\text { (6) } \quad\left(D^{\prime} D\right)^{-1} D V D\left(D^{\prime} D\right)^{-1}
$$

where all functions are evaluated at the true value of the parameters $(\beta, \beta, g, 9, \phi) . A$ consistent estimate of the variance covariance matrix is obtained by substituting $\left(b, b_{b}, g_{n}, \rho_{n}, \phi_{n}\right)$ for $\left(\beta, \beta_{p}, g, \rho_{1}\right)$ in equations (1) to (3), computing the sample analogues to the expectations in (3), (4), and (5), and substituting these into (6).

Note that if we were to ignore the last four terms in (3) (set them equal to zero); then this variance covariance matrix would be identical to the variance covariance matrix we would obtain if we knew $(\beta, g, \mathscr{g}, \emptyset)$, substituted there true values into the definition of $m()$ in (1), and set the resulting equation equal to zero. The last four terms in (3) provide adjustments for the fact that we use estimators of $g, \mathcal{P} \phi$, and $\beta_{p}$ rather than there true values.

o. 


\section{REFERENCES}

Andrews, D.W.K., 1990, "Asymptotic for Semiparametric Econometric Models II: Stochastic Equicontinuity and Nonparametric Kernel Estimators", Cowles Foundation Discussion Paper No. 909R.

Andrews, D.W.K., 1991, "Asymptotic Normality of Series Estimators for Nonparametric and Semiparametric Regression Models", Econometrica, Vol. 59 No. 2, March 1991, pp. $307-346$.

Baldwin, J.R. and P.K. Gorecki, (1989), "Job Turnover in Canada's Manufacturing Sectors", Statistics Canada, Research Paper Series, 1989.

Bierens, H.J. (1987),"Kernel Estimators of Regression Functions," in Advances in Econometrics - Fifth World Congress, Vol. I, ed. by T. F. Bewely, Cambridge: Cambridge University Press.

Brock, G. (1981), The Telecommunications Equipment Industry; The Dynamics of Market Structure, Cambridge, Massachusetts: Harvard University Press, 1981.

Davis, S., and J. Haltwinger,(1990); "Gross Job Creation, Gross Job Destruction: Microeconomic Evidence and Macroeconomic Implications," NBER Macroeconomics Annual, 5, 123-168.

Dunne, T., Roberts, M. and L. Samuelson (1988), "Patterns of Firm Entry and Exit in U.S. Manufacturing Industries" Rand Journal of Economics, Vol. 19, No. 4, Winter 1988, pp. 495-515.

Ericson, R. and A. Pakes, (1989), "An Alternative Theory of Firm and Industry Dynamics," Discussion Paper No. 445, Columbia University, 1989.

Geroski, P.A. (1991); "The Empirical Analysis of Entry, Strategic Deterrence, and Market Selection", mimeo London Business School.

Gray, W. (1989), "Productivity Data Base", mimeo, Clark University.

Griliches, Z. (1957), "Specification Bias in Estimates of Production Functions," Journal of Farm Economics, Vol. 39, pp 8-20.

Griliches, Z. (1967), "Production Functions in Manufacturing: Some Preliminary Results," in M. Brown, ed., The Theory and Empirical Analysis of Production, New York: Columbia University Press for NBER, 1967.

Hulten, C.R. and F. Wykoff(1981), "The Measurement of Economic Depreciation" in Depreciation, Intlation, and Taxation of Income from Capital. C.R. Hulten, ed., Urban Institute Press, Washington, D.C., 1981.

Hopenhayn, H. and R. Rogerson, (1990); "Labor Turnover and Policy Evaluation in a Model of Industry Equilibrium", mimeo, Graduate School of Business, Stanford University, 1990. 
Lambson, V.E.(forthcoming), "Industry Evolution with Sunk Costs and Uncertain Market Conditions", the Review of Economic Studies.

Jovanovic, B. (1982), "Selection and Evolution of Industry," Econometrica, Vol. 50, No. 3, May 1982, pp. 649-670.

Marschak, J. and W. H. Andrews (1944), "Random Simultaneous Equations and the Theory of Production," Econometrica, Vol. 12, No. 3-4, July-October 1944, pp. 143-205.

Maskin, E. and J. Tirole (1988), "A Theory of Dynamic Oligopoly: I \& II," Econometrica, Vol. 56, No. 3, May 1988, pp. 549-600.

McGuckin, R. and G. Pascoe (1988), "The Longitudinal Research Database (LRD): Status and Research Possibilities," U.S. Bureau of the Census, Center for Economic Studies Discussion paper, CES 88-2, July 1988.

National Academy of Engineering (1984), The Competitive Status of the U.S. Electronics Industry, Washington, D.C.: National Academy Press, 1984.

National Telecommunications and Information Administration (1988), NTIA Telcom 2000: Charting the Course for a New Century, Washington, D.C.: U.S. Department of Commerce, October, 1988 .

Newey, W.K. (1991a); "The Asymptotic Variance of Semiparametric Estimators", MIT Department of Economics Working Paper No. 583.

Newey W.K. (1991b), "Consistency and Asymptotic Normality of Nonparametric Projection Estimators", preprint M.I.T.

Noll, A. M. (1987), "Bell System R\&D Activities: The Impact of Divestiture", Telecommunications Policy, June 1987.

Pakes, A. (1991), "Dynamic Structural Models, Problems and Prospects part II: Mixed Continuous-Discrete Control Problems, and Market Interactions, " forthcoming in Advances in Econometrics, C. Sims, ed., forthcoming.

Pakes, A. and P. McGuire (1990); "Computation of Markov Perfect Nash Equilibria: Numerical Implications of A Dynamic Differentiated Product Model", mimeo, Yale University.

Pakes, A. and S. Olley (1991); "A Limit Theorem for a Smooth Class of Semiparametric Estimators", mimeo, Yale University.

Robinson, P.M. (1988), "Root-N Consistent Semiparametric Regression," Econometrica, Vol. 55 , No. 4 July 1988 , pp. $931-954$.

Sciberras, E. and B. Payne (1986), Telecommunications Industry, Chicago, Illinois: St. James Press, 1986.

Silverman, B.W. (1986), Density Estimation for Statistics and Data Analysis, London: Chapman and Hall, 1986.

Temin, P. (1987), The Fall of the Bell System, with Louis Galambos, Cambridge: 
Cambridge University Press, 1987.

Wedervang, F. (1965), Development of a Population of Industrial Firms, Oslo, Norway: Scandinavian University Books, 1965. 